Dist. Category UC-90C

\title{
MATERIALS RESEARCH FOR THE CLEAN UTILIZATION OF COAL
}

\author{
QUARTERLY PROGRESS REPORT
}

October - December 1979

\author{
Samuel J. Schneider \\ Project Manager
}

\author{
Center for Materials Science \\ National Bureau of Standards \\ Washington, D. C. 20234
}

\section{PREPARED FOR THE UNITED STATES DEPARTMENT OF ENERGY}

\author{
Office of Advanced Research and Technology
}

Under Contract No. EA-77-A-01-6010

"This report was prepared as an account of work sponsored by the United States Government. Neither the United States nor the United States Department of Energy, nor any of their employees, nor any of their contractors, subcontractors, or their employees, makes any warranty, expressed or implied, or assumes any legal liability or responsibility for the accuracy, completeness, or usefulness of any information, apparatus, product or process disclosed, or represents that its use would not infringe privately owned rights." 

TABLE OF CONTENTS

PAGE

I. SUMMARY OF PROGRESS TO DATE . . . . . . . . . . 1

II. DETAILED DESCRIPTION OF TECHNICAL PROGRESS. . ..... 3

4. Failure Prevention ............ 3

5. Creep of MHD Refractories. . . . . . . . 3

6. Electrical Transport Mechanisms in Slag. . . . . 8

7. Corrosion of Downstream MHD Components . . . . 17 

4. Failure Prevention

b. Materials Properties Data Center

A test set of MHD data has been assembled for use in benchmarking the six remaining computer-services vendors. Some eighty data sets were prepared, keyboarded, corrected and transferred to magnetic tape.

The tapes, each containing over 5000 lines of information, were delivered to the vendors so that they all would be working with the same data base for comparison testing. Additional amendments to the solicitation for vendor's services have been required and issued.

Routine procedures for handling the contractors' research reports have continued as usual.

\section{Creep of MHD refractories}

Work was concentrated on completing the evaluation of the chrome-spinel refractory (Corhart RFG); this includes creep and swelling measurements at $1400{ }^{\circ} \mathrm{C}, 1500{ }^{\circ} \mathrm{C}$ and $1600{ }^{\circ} \mathrm{C}$. The results indicated considerable deformation at all testing temperatures. The specimen tested at 91 psi and $1600{ }^{\circ} \mathrm{C}$ failed catastrophically.

A technical report on these measurements will be prepared during the next quarter. In addition, four new furnaces will be installed for the planned expansion of the creep facilities.

\section{Electrical Transport Mechanisms in Slag}

The dependence of the electrical conductivity of $\mathrm{Y}_{95} \mathrm{Ca}_{0} \mathrm{CrO}_{3}$ on oxygen pressure in the range of pressures from $10^{\circ}$ to $10^{-6}$ atmospheres have been completed for temperatures from $1300^{\circ}$ to $1600{ }^{\circ} \mathrm{C}$. The apparatus has been rebuilt to allow measurements in the high temperature range at oxygen pressure from $10^{-6}$ to $10^{-15}$ atmospheres.

A three probe electrochemical cell has been constructed and the electrochemical effects measured at a temperature of $1254{ }^{\circ} \mathrm{C}$. This ce11 allows the measurement of slag-electrode voltages as a function of time and ultimate analyses of the electrochemical effects.

The first series of experiments on the electrical conductivity of Bow $\mathrm{NH}$ slag has been completed. The conductivity at low temperatures (below $1100^{\circ} \mathrm{C}$ ) depends on the crystalline state of the slag. The conductivity at high temperature (above $1400^{\circ} \mathrm{C}$ ) is independent of the oxygen pressure and of the amount of $\mathrm{K}$ present at least up to $6 \%$ by weight.

\section{Corrosion of Downstream MHD Components}

Type 304 stainless steel tubes, cooled to $400{ }^{\circ} \mathrm{C}, 500{ }^{\circ} \mathrm{C}$ and $590{ }^{\circ} \mathrm{C}$, were exposed to fuel rich and oxygen rich hot gas streams seeded with a mixture of $80 \%$ by weight $\mathrm{K}_{2} \mathrm{CO}_{3}$ and $20 \%$ by weight $\mathrm{K}_{2} \mathrm{SO}_{4}$. Optical and SEM and EDX analysis revealed differences, geometrical and chemical, 
in the deposit formed on the tubing on a result of the tube temperature and the gas stream stae. Tubes at the higher temperatures had thinner ceposits as did tubes exposed to the fuel rich gas streams. Information with respect to the distribution of $\mathrm{Fe}, \mathrm{Cr}$ and $\mathrm{Ni}$ in the reaction zone (stainless steel-deposit interface) was also obtained with Fe appearing to be the species penetrating most deeply into the salt deposit.

In the coming quarter exposure tests, similar to those conducted on type 304 stainless steel, will be initiated on type 316 stainless steel. 
4. Failure Prevention

b. Materials Properties Data Center (MHD materials effort) H. M. Ondik and A. Perloff, 565

Progress: Work on the MHD state-of-the-art has had to be set aside temporarily because the Data Center staff has had to be involved in the preparation of test data for the use of the computer vendors benchmark test sessions. Although some eighty data sets had been delivered to the vendors on typed sheets, it became necessary to provide these data on magnetic tape. The drafting of the requirements for the amendment and the keyboarding, proofreading, correcting of tape cassettes, and the transfer of the data to computer magnetic tape reels have occupied much of the time and effort of the personnel during the early part of the quarter. Legal procedures also required the issuance of an amendment to the original solicitation for the vendors' services, as well as information for their use. Benchmark sessions were scheduled and then postponed because of questions submitted by the vendors. A good bit of time was required to draft the answers to the vendors' technical questions and to provide supplemental information which we hope will give the vendors sufficient information to perform. The technical data which we have is rather more complicated than the material with which most commercial vendors deal. Although there has been some time for work on the MHD manuscript, these periods have not been long enough to be efficiently productive. Much time has been consumed in communicating with Main Commerce, and through that office, with the vendors. Since no direct communication may be made with vendors, everything must go through the Commerce contract officer. Routine procedures for handling the contractors' research reports have continued as usual.

Plans: Work on the MHD paper will continue as time permits, allowing for interruptions due to the computer services procurement procedure. It is expected that most of January will be occupied with the procurement since benchmark sessions are currently expected to begin about the middle of January. This next quarter should see the awarding of a contract for computer services.

5. Creep of MHD Refractories (N. J. Tighe, C. L. McDaniel and S. M. Wiederhorn, 562.00)

Progress: Work during the quarter was concentrated on completing the evaluation of the chrome-spinel refractory designated Corhart RFG. This evaluation included creep measurements and swelling measurements at $1400^{\circ} \mathrm{C}, 1500^{\circ} \mathrm{C}$ and $1600^{\circ} \mathrm{C}$ and identification of structural and compositional changes after exposure. For the magnesia spinel designated Corhart $\mathrm{X}-317$ creep measurements and compressive yield measurements were continued.

Experimental Procedure: Creep measurements were made on cored samples 3 inches long with a 1 inch reduced cross-section using a dead-weight machine. Compressive yield results were obtained on reduced crosssection samples in an Instron machine with a cross head speed of 
$2 \times 10^{-4} \mathrm{in} / \mathrm{min}$. The structural and compositional data were obtained using $x$-ray powder diffraction, energy dispersive $x$-ray analysis (EPAX) in a scanning electron microscope.

Results: The RFG refractory exhibited considerable creep at $1400{ }^{\circ} \mathrm{C}$, $\overline{1500{ }^{\circ} \mathrm{C}}$ and $1600{ }^{\circ} \mathrm{C}$. Some of the data obtained from specimen measurements during loading are shown in Fig. 1. The plots show data obtained from the dialometric measurements and from dimensional measurements of the specimen. The specimen tested at 91 psi at $1600{ }^{\circ} \mathrm{C}$ failed catastrophically in approximately 2 hours. The actual deformation of the specimens is shown in the light micrographs shown in Fig. 2. In these pictures, the cracking and swelling are seen clearly.

From the x-ray diffraction patterns, of as-received and exposed specimens, it was found that the RFG undergoes a phase transformation during heating at $\geq 1400{ }^{\circ} \mathrm{C}$. The as-received refractory has Mg0 plus two spinels in solid solution: a chromium rich spinel $\left(\mathrm{MgCr} \mathrm{Al}_{2}-\mathrm{O}_{4}\right)$ and an iron rich spinel ( $\mathrm{Mg} \mathrm{Fe} \mathrm{Al}_{2} \mathrm{O}_{4}$ ). This material is maghetic because of the iron rich spinel. $\mathrm{Af}_{\text {Afer }}$ annealing at $1400{ }^{\circ} \mathrm{C}$ the RFG transforms so that only one spinel ( $\mathrm{Mg} \mathrm{Cr} \mathrm{Al}_{2}-\mathrm{O}_{4}$ ) is found and the material is non-magnetic indicating a change ih $\gamma$ alence of the iron. This phase transformation and structural change can account for the swelling discussed in the last quarterly report. The structure and composition of RFG refractory brick samples taken from the failed run in the Montana State air-preheater test rig changed considerably from the top to the bottom. These samples were designated 2-3,5-3, 14-3, 23-3 and 49-3, where the first number indicates the brick number from the top of the stack. The changes result from both the thermal treatment and the interaction with coal slag. Although the analyses are not complete, it is clear from the examples shown in Fig. 3 that slag penetration occurred throughout the stack. The slag adhering to the top bricks was identified as $\mathrm{Mg}_{2} \mathrm{SiO}_{4}$ (olivine) plus a trace of Ca.Al.Si.0x plus amorphous material whereas the slag found on the lower bricks was identified as $2 \mathrm{CaO} \cdot \mathrm{Al}_{2} \mathrm{O}_{3} \cdot \mathrm{SiO}_{2}$ gehlenite with a trace of Ca.Al.Siox. These two phases have differeht melting temperatures. The RFG brick exhibited compositional changes from two spinels plus $\mathrm{MgO}$ and $\mathrm{Mg}_{2} \mathrm{SiO}_{4}$ to a single spinel plus $\mathrm{MgO}$ and $\mathrm{Mg}_{2} \mathrm{SiO}_{4}$.

The complete analysis of the data on the RFG refractory is too lengthy for this report and will be compiled and published as a separate report. Failure of the RFG in service can result from a combination of structural and compositional changes which take place during exposure at high temperatures and under load in a slagging environment. The presence of slag during the exposure can increase the degredation rate of the material, because it can infiltrate the microstructure and cause chemical and physical changes.

The magnesia spinel refractory designated Corhart X-317 exhibits greater creep resistance than the RFG. The initial compressive yield tests indicate a yield drop at about $2 \%$ strain at a stress of $8.8 \mathrm{Ksi}$ (62 $\mathrm{MPa}$ ) at $1400{ }^{\circ} \mathrm{C}$. A test run at $1400{ }^{\circ} \mathrm{C}$ for 725 hours showed total creep of approximately $0.1 \%$ at a stress of 200 psi.

Plans: During the next quarter a report on the RFG refractory will be prepared. The creep tests on the $X-317$ will be continued. The four new furnaces, which arrived the end of December, will be set up and made ready for the delivery of the furnace control system. 


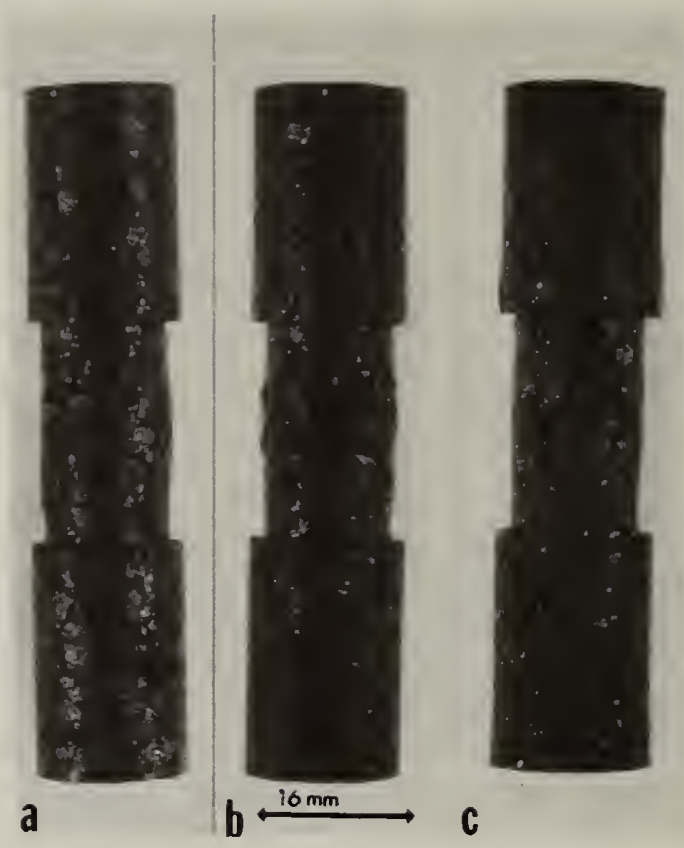

Fig. 2. Refractory RFG specimens from creep tests (a) $1400^{\circ} \mathrm{C}, 150$ psi, $363 \mathrm{hr} 7.5 \%$ deformation (b) $1500^{\circ} \mathrm{C}$, $92 \mathrm{psi}, 133 \mathrm{hr}, 8.4 \%$ deformation (c) $1600^{\circ} \mathrm{C}, 51 \mathrm{psi}, 63 \mathrm{hr} 9.1 \%$ deformation. 

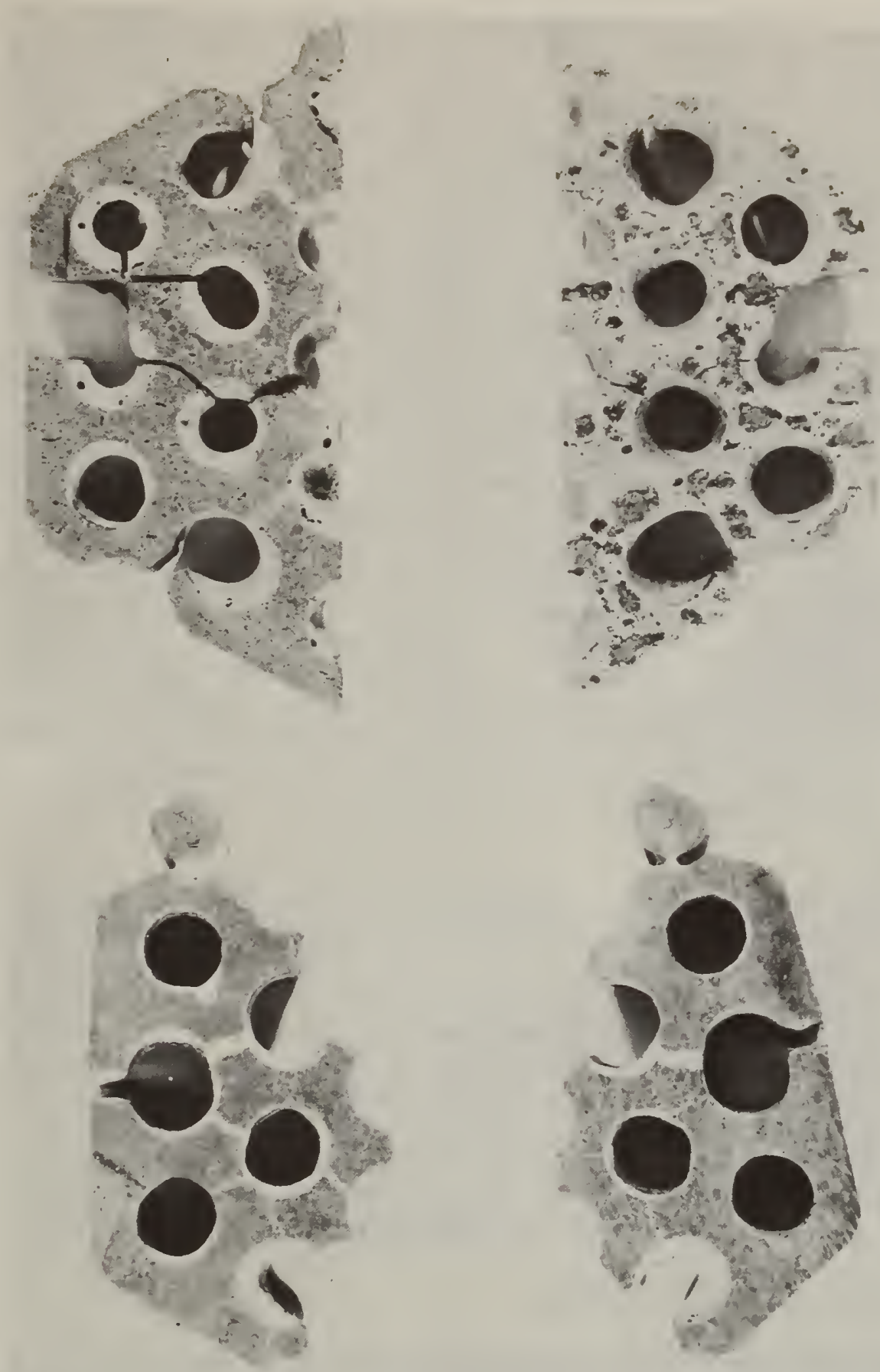

Fig. 3. Top and bottom surfaces of 1 in thick brick sections from Montana State test rig (a) brick 5-3 near top (b) brick 49-3, near bottom. 


\section{Progress}

a. Electrical Conductivity of $\mathrm{YCrO}_{3}$.

The dependence of the electrical conductivity of $\mathrm{Y} .{ }_{9} \mathrm{Ca} .{ }_{5} \mathrm{CrO}_{3}$ on oxygen pressure in the range of pressures from $10^{\circ}$ to $10^{-} 6^{\circ}$ atmospheres have been completed for temperatures from $1300{ }^{\circ} \mathrm{C}$ to $1600{ }^{\circ} \mathrm{C}$. In order to obtain high density $\mathrm{YCrO}_{3}$, it is necessary to sinter it in a highly reducing atmosphere at about $1700^{\circ} \mathrm{C}$. This atmosphere may be forming gas $\left(5 \% \mathrm{H}_{2}-95 \% \mathrm{~N}_{2}\right)$ which results in a low pressure of $\mathrm{O}_{2}$ of $10^{-14}$ to $10^{-15}$ atmospheres. Material produced under these conditions has a high density (98\% theoretical) and is very hard. Subsequent oxidation renders the material much softer and it sometimes contains hair line cracks. The material with $5 \% \mathrm{Ca}$ added is still single phase when oxidized but the oxygen take up must cause enough change in the lattice parameters in certain areas to cause a stress build up with the resultant physical sample degradation. This aspect of the problem is being investigated by the Crystal Chemistry Section of CMS at NBS. The dimensional changes associated with this effect are very small and cannot account for the increase in conductivity noted in the last quarterly report for the the $1600{ }^{\circ} \mathrm{C}$ temperature point in an atmosphere of air. The continual drift upward in conductivity noted for the $1600{ }^{\circ} \mathrm{C}$ point in air was not evident at any temperature in 900 and 2 ppm oxygen in nitrogen.

The sample holder has been revised using $0.25 \mathrm{~mm}$ molybdenum wire instead of platinum. The wire leads are anchored in the sample with platinum. The phase diagram of Pt-Mo shows a eutectic mixture at about 25 atomic \% platinum and at a temperature of $2080{ }^{\circ} \mathrm{C}$. The conductivity vs. pressure measurements will be made using a maximum temperature $\left(1600^{\circ} \mathrm{C}\right)$ well below this eutectic point. No reaction is expected. the previous measurements in the oxygen pressure range of $10^{7}$ to $10^{-15}$ ppm $\mathrm{O}_{2}$, the platinum wire leads failed. The platinum contacts in the sample always remained intact, however. These measurements at the low oxygen pressure will be made as soon as the oxygen sensor necessary for measuring these low pressures is repaired.

\section{b. Corrosion of $\mathrm{YCrO}_{3}$ in $\mathrm{Slag}$}

In the last quarterly report, the results of a test on an electrochemical cell composed of $\mathrm{YCrO}_{3}$ electrodes and Bow $\mathrm{NH} \mathrm{slag} \mathrm{with} 20 \%$ $\mathrm{K}_{2} \mathrm{SO}_{4}$ added were reported. This test was carried out at $1343^{\circ} \mathrm{C}$ and resulted in considerable cathode reaction but with not much reaction at the anode. A new cell has been constructed and tested using the same materials (Bow NH slag with $20 \% \mathrm{~K}_{2} \mathrm{SO}_{4}$ electrolyte and $\mathrm{Y}_{.9}{ }_{5} \mathrm{Ca} .{ }_{5} \mathrm{CrO}_{3}$ electrodes) but with a slightly different configuration. This cell contains 3 electrodes, two of which are active (anode and cathode at each end of the cell) and one which is passive (center of cell) which carries no current. This allows for direct measurement of the potential distribution along the length of the cell i.e. for potentials between 
anode and reference and between reference and cathode. No polarization should result on the reference electrode since no current enters or leaves at this point. There may be degradative chemical reactions, however, at the reference electrode not associated with the transport of charge. These measurements were carried out at $1254{ }^{\circ} \mathrm{C}$ and with a power supply providing a constant DC voltage source of 118 volts. The results are shown in Figure 1. Initial current was about $75 \mathrm{~mA}$ which would correspond to approximately $0.5 \mathrm{~A} / \mathrm{cm}^{2}$ current density at the electrode slag interface. This current drops off to about $20 \%$ of its original value or $15 \mathrm{~mA}$ in the first 20 minutes of cell operation and finally down to about $8 \mathrm{~mA}$ after the total test time of 3 hours and 50 minutes. In the initial 20 minute period, the anode to reference voltage increased to $110 \mathrm{~V}$ i.e. within 8 volts of the total applied potential while the reference to cathode voltage dropped to about 8 volts. It is obvious that a large polarization potential has built up at the anode. This is most likely due to the zone near the anode that is silica rich or depleted in movable positive ions such as iron and potassium. On the other hand, positive ion transport toward the cathode lowers the potential barrier there, as well as the bulk conductivity of the slag. This effect has been observed before using other materials $(1,2,3)$ and is certainly a contributing factor in the cathode electrode segment voltage nonuniformities observed in some of the AVCO tests reported in the 16th Symposium on Engineering Aspects of MHD held at the University of Pittsburgh in May 1977.

Electrical conductivity measurements on Bow NH slag discussed later in this section of the report under Slag Electrical Conductivity (Part C) indicates that a sizeable fraction of the charge carried in slag is transported by ions. The basic question in MHD electrode materials is: How can this mass transport and its associated electrochemical effects be handled? One interesting aspect of the situation is to ascertain if any of the resulting electrochemical effects are reversible and under what conditions. Preliminary indications from the AVCO generator experiments show that the effects causing cathode voltage nonuniformities can be reduced by running the channel at no load (open circuit) for a period of time. An electrochemical cell for investigating the reversibility of these effects is under construction.

\section{c. Slag Electrical Conductivity}

The electrical conductivity of Bow NH slag with $20 \% \mathrm{~K}_{2} \mathrm{SO}_{4}$ added to the melt has been completed. Figure $2 a$ and $b$ show radiographs of the crucible containing the slag before and after the experiment. No observable physical change has taken place during the experiment. Figure 3 shows the conductivity data as a function of temperature. All data was taken at a partial pressure of oxygen of $2 \times 10^{-6}$ atmospheres. The temperature from which the slag was furnace quenched to $900^{\circ} \mathrm{C}$ is indicated on the graph. The conductivity data at reduced oxygen pressure is not quite so quench temperature dependent as that data for the conductivity in air shown in the last quarterly report (July-Sept. 1979). The magnitude and the general trend is the same, however. There appears to be two 
crystalline phases contributing to the conductivity. In the reduced $\mathrm{O}_{2}$ pressure experiment, a break in the conductivity curve occurs near

$1160{ }^{\circ} \mathrm{C}$ for all data; the break becoming more pronounced for the runs where the sample is quenched to $900{ }^{\circ} \mathrm{C}$ from soak temperatures above $1400{ }^{\circ} \mathrm{C}$. A11 data shown on the graph is taken with increasing temperature after being quenched to $900{ }^{\circ} \mathrm{C}$ and cooled slowly to the lower temperature $\left(\sim 500{ }^{\circ} \mathrm{C}\right)$. The data below $800{ }^{\circ} \mathrm{C}$ may be affected by cracks in the slag body formed by quenching to $900{ }^{\circ} \mathrm{C}$ and subsequent cooling to lower temperatures. Cracking appears to be more severe in those samples with the $\mathrm{K}_{2} \mathrm{SO}_{4}$ added. It would be interesting to see how the coefficients of thermal expansion for these seeded and unseeded slags differ. X-Ray diffraction measurements (courtesy of $H$. Parker, Center for Materials Science, Solid State Chemistry Group) show that the phase composition below $1180{ }^{\circ} \mathrm{C}$ is a kalsilite like phase (probably $\mathrm{KAlSiO}_{4}$ ) and spinel $\left(\mathrm{Fe}_{3} \mathrm{O}_{4}\right)$ for that material quenched from $1426{ }^{\circ} \mathrm{C}$. This kalsilite like phase was not detected in the slag measured in an air atmosphere and quenched from nearly the same temperature $\left(1420{ }^{\circ} \mathrm{C}\right)$. The spinel $\left(\mathrm{Fe}_{3} \mathrm{O}_{4}\right)$ was detected in the sample measured in air. The interesting and unusual aspect is that the slag conductivities for Bow NH slag with and without seed and measured in air and in an atmosphere of $2 \times 10^{-6} \mathrm{O}_{2}$ partial pressure are the same as a function of temperature above $1400^{\circ} \mathrm{C}$. If the potassium ion conductivity is the predominant mechanism for charge transport, above $1400{ }^{\circ} \mathrm{C}$, the samples containing added $\mathrm{K}_{2} \mathrm{SO}_{4}$ should have a higher conductivity. Chemical analysis for $K$ and $S$ of the Bow NH slag with 20 wt. $\% \mathrm{~K}_{2} \mathrm{SO}_{4}$ added to the melt before and after the electrical measurement $\left(2 \times 10^{-6}\right.$ atmos $\left.0_{2}\right)$ are given in Table 1 .

Table 1

$\begin{array}{lcc} & \% \mathrm{~K} & \% \mathrm{~S} \\ \text { Before conductivity measurement } & 6.34 & .022 \\ \text { After conductivity measurement } & 5.99 & 0.12\end{array}$

The magnitude of sulfur detected in each case was below the accurate limits of detection. It apparently leaves during initial melting of the slag and $\mathrm{K}_{2} \mathrm{SO}_{4} \mathrm{mix}$. The reason for the discrepancy between the amount of $K$ added $(9 \%)$ and that detected in the analys is is unknown. If the conduction mechanism is predominantly electronic above $1400{ }^{\circ} \mathrm{C}$ and due to the iron ion ratio $\mathrm{Fe}^{+} / \mathrm{Fe}^{+}{ }_{3}$ one would expect a higher conductivity in that sample measured in a partial pressure of oxygen of $2 \times 10^{6}$ atmospheres. Johnson (4) has reported an $\mathrm{Fe}^{+} 2 / \mathrm{Fe}^{+}{ }_{3}$ ratio at $1450{ }^{\circ} \mathrm{C}$ of 1.6 for an oxygen pressure of $10^{-6}$ atmospheres and of 0.13 for an air atmosphere. This gives a ratio change of near 13 which should be reflected in the conductivity if there is exchange between the iron ions of different valence. The measured conductivity of the slag above $1400{ }^{\circ} \mathrm{C}$ is not likely to be due to oxygen ions since the conductivity is not oxygen pressure independent. The slag sample at high temperature is a disordered structure (molten) and it is not surprising that the electron exchange is small between $\mathrm{Fe}^{+}{ }_{2}$ and $\mathrm{Fe}^{+}{ }_{3}$. Simnad, Derge, and George (5) in transport measurements on iron in silicate slags conclude that 
the transport number of the iron ions $\mathrm{Fe}^{+} 2$ is one and therefore that the current is being carried almost completely by these ions. The ionic radius of $\mathrm{K}$ is large $\left(1.33 \AA\right.$ ) while that of $\mathrm{Fe}^{+}{ }_{2}$ and $\mathrm{Fe}^{+} 3$ is $0.74 \dot{A}$ and $0.64 \dot{A}$, respectively. This difference in ionic radii coupled with the difference in ionic charge may make the iron ion the predominant charge carrier in the molten slag.

The relative amounts of $\mathrm{Fe}^{+} 2$ to $\mathrm{Fe}^{+} 3$ then would have a secondary effect on the electrical conductivity. The total iron content, however, would affect the magnitude of the conductivity. This correlation was pointed out earlier by Bates (6) in his analysis of early slag conductivity work done by Frederikse and Hosler (7).

d. Other Activities

1. During the course of channel proof tests in preparation for the 3rd Joint US-USSR Materials Test in the U.02 MHD facility in Moscow, the electrical conductivity of $\mathrm{Sr}_{0.9} \mathrm{La}_{0.1} \mathrm{Zr}_{0 .}{ }_{7} \mathrm{Cr}_{0 .}{ }_{3} \mathrm{O}_{3}$ was measured as a function of temperatue and oxygen pressure. This material was prepared by $A$. T. Research and no details were given on its preparation. The data was presented in quarterly report Oct-Dec. 1977 to DoE. An inquiry was received from $\mathrm{Dr}$. H. Shapiro from TRW concerning this material with regard to its large range showing a positive temperature coefficient of resistance in an air atmosphere. Another sample was sent from TRW and the conductivity measured during this reporting period. The resulting data is shown in Figure 4. The range showing a positive temperature coefficient of resistance is reduced considerably and shows a hysteresis effect with increasing or decreasing temperature indicative of a reversible phase change.

2. During the week of October $8 \mathrm{th}$, W. R. Hosler attended the joint 16th International Thermal Conductivity Conference and the 7 th International Thermal Expansion Symposium held in Chicago at the IIT Research Institute on Nov. 7-9.

3. On December 5 and $6, W$. R. Hosler participated as a panel member for Materials in the review of the DoE sponsored work of MERDI at Butte, Montana. The review was held at Montana State University, Bozeman, Montana.

\section{References}

(1) Electrochemical Effects in Simulated Slag Flow W. Capps, D. A. Kauffman, and W. R. Hosler, Quarterly Report for the period April-June 1978 to DoE under contract No. EA-77-A-01-6010.

(2) Discharge Characteristics of Slagging Metal Electrodes J. K. Koester and R. M. Nelson, 17th Symposium on Engineering Aspects of MHD. Stanford University, Stanford, California. March 27-29, 1978. 
(3) Electrochemical Corrosion of MHD Electrodes in Slags

L. D. Cadoff, D. B. Rossing, and H. D. Smith, 17th Symposium on

Engineering Aspects of MHD, Stanford University, Stanford, California. March 27-29, 1978.

(4) Oxidation - Reduction Equilibria in Iron Containing Glass

W. D. Johnson, Journal of American Ceramic Society, Vol. 47, No. 4, Apri1 1964.

(5) Ionic Nature of Liquid Iron - Silicate Slags AIME Transactions

M. T. Simnad, G. Derge, and I. George, Journal of Metals, 200,

p. 1386, Dec. 1954.

(6) Private communication.

(7) Electrical Conductivity of Coal Slag

H. P. R. Frederikse and W. R. Hosler, Journal of American Ceramic

Society, Vol. 56, No. 8, August 1973.

Plans

The electrical conductivity of $\mathrm{YCrO}_{3}$ doped with $5 \% \mathrm{Ca}$ on the $\mathrm{Y}$ site in the oxygen pressure range of $10^{-6}$ to $10^{-15}$ atmospheres will be completed. Experimental difficulties here have been largely overcome and the outcome measurements may depend on the physical stability of the material upon going from an oxidizing to a reducing atmosphere.

The work on the slag electrical conductivity will continue. A decision must be made whether to continue with the Bow NH slag (doping or increasing iron content, etc.) or begin to study extensively the conductivity mechanisms in low iron high calcium slag (Rosebud).

The electrochemical experiments involving slag and electrode materials will continue particularly with respect to the possible reversibility of these effects or with respect to the time limits involved when electrochemical reactions degrade conductivities far enough to limit usefulness. 


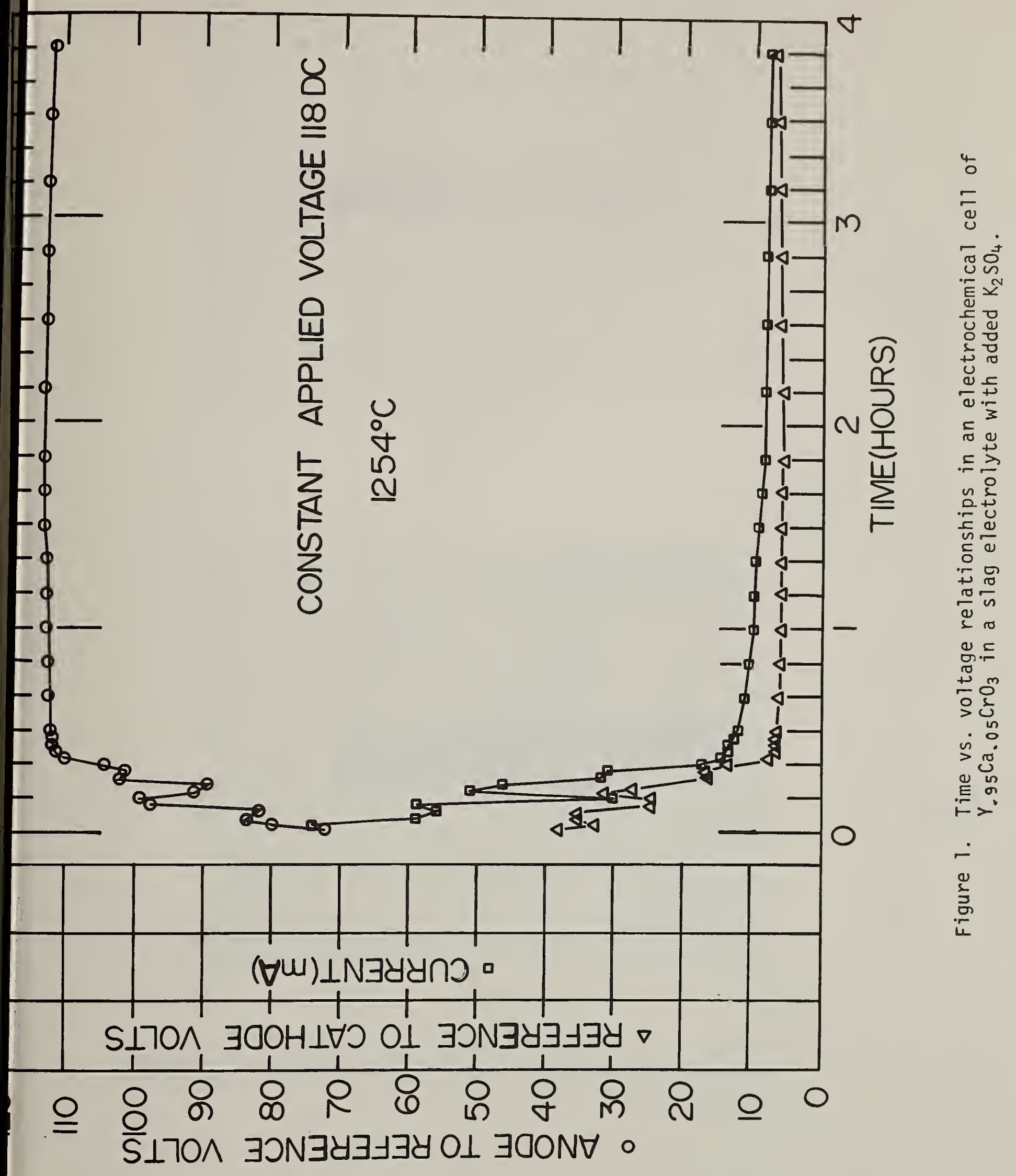




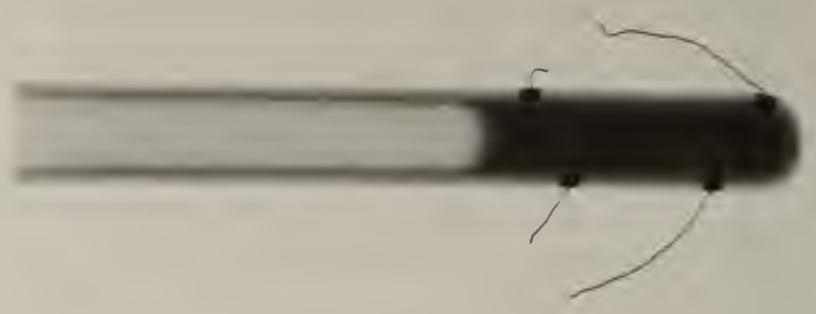

Figure 2. Radiograph of crucible showing slaa fill and electrode configuration before (a) and after (b) electrical conductivity measurements. 


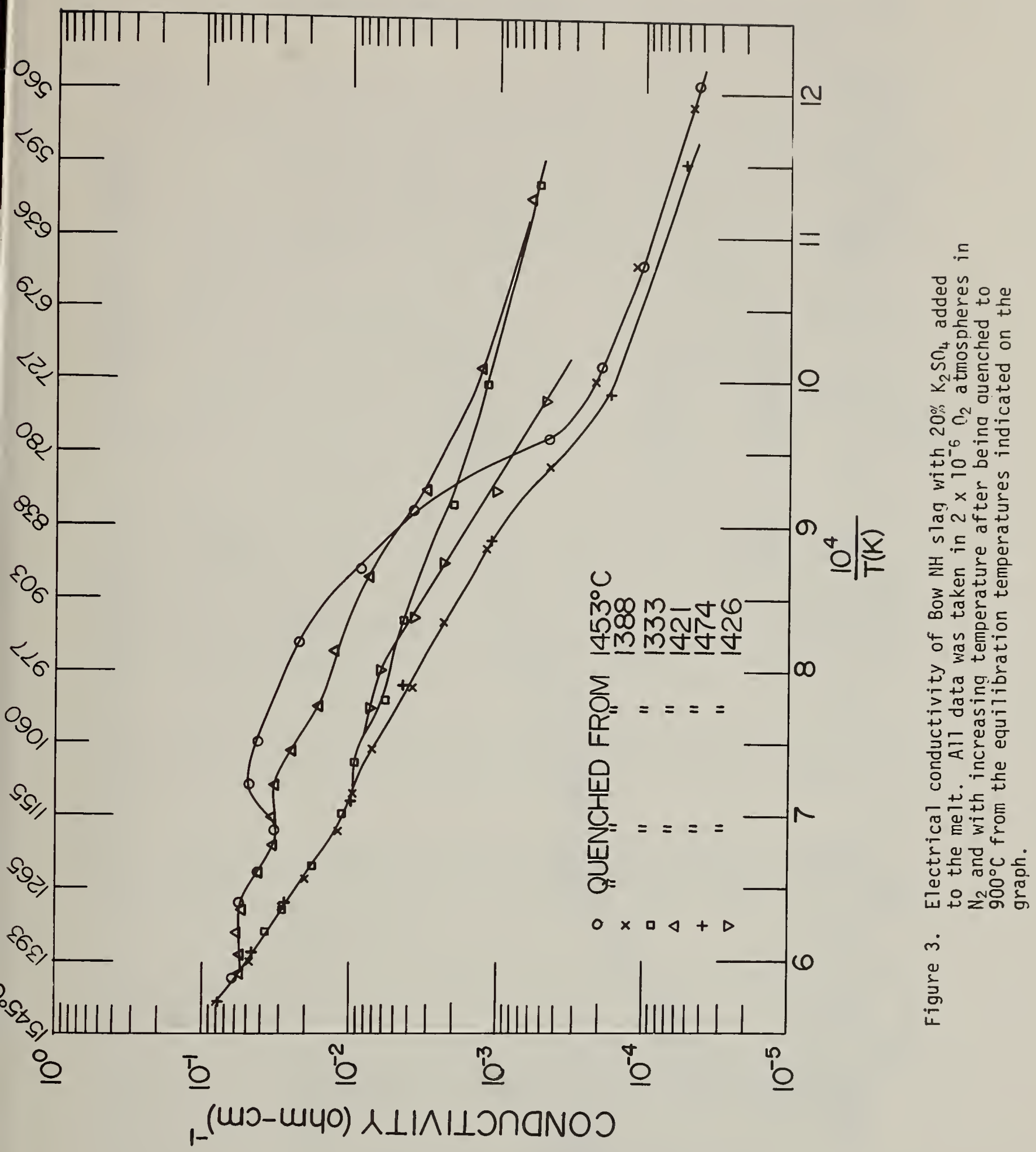




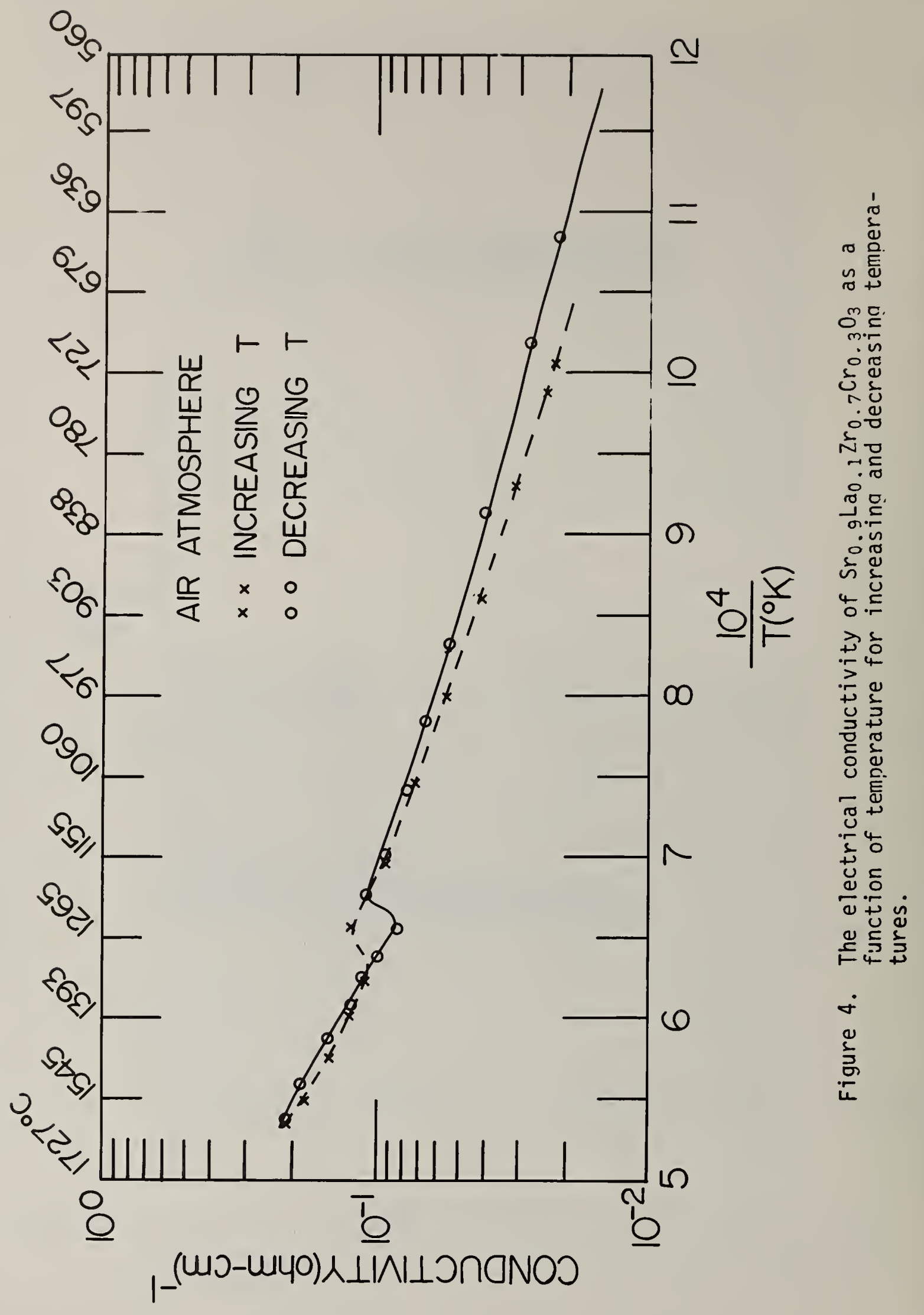


Progress: Type 304 stainless steel tubular specimens were exposed to a seeded oxygen-propane fueled hot gas stream under varied conditions and then analyzed by SEM and EDX techniques. Total exposure time to the hot gas stream was 4 hours with the first 25 minutes of this period being used to seed the gas stream with $250 \mathrm{~g}$ of a mixture of $80 \%$ by weight $\mathrm{K}_{2} \mathrm{CO}_{3}$ with $20 \%$ by weight $\mathrm{K}_{2} \mathrm{SO}_{4}$. Six stainless steel 304 specimens were têsted under these general conditions. Three of the tubular specimens were exposed to an oxygen rich gas stream environment at tube temperatures of $400{ }^{\circ} \mathrm{C}, 500^{\circ} \mathrm{C}$ and $590^{\circ} \mathrm{C}$, respectively. The remaining three samples were exposed to a fuel rich gas stream environment at $400{ }^{\circ} \mathrm{C}, 500{ }^{\circ} \mathrm{C}$ and $590{ }^{\circ} \mathrm{C}$. Specimen temperatures were maintained at the desired value by internal air cooling and were monitored through a Pt/Pt10\%Rh thermocouple welded into the specimen wal1. In the vicinity of the test specimen the gas stream temperature was maintained at approximately $1300{ }^{\circ} \mathrm{C}$ as monitored through a $\mathrm{Pt} / \mathrm{Pt} 10 \% \mathrm{Rh}$ thermocouple. The fuel rich and the oxygen rich states were accomplished by varying oxygen to propane flow rate ratios.

To reduce external contamination of the samples and hydration of the $\mathrm{K}_{2} \mathrm{CO}_{3}$ in the coatings formed during seeding of the hot gas stream, the samples were removed from the test rig upon cool down to about $40{ }^{\circ} \mathrm{C}$ and potted immediately in epoxy. Metallographic specimens were then prepared from sections of the stainless steel tube taken approximately $10 \mathrm{~mm}$ from the midpoint position in the hot zone. The specimens were then ground and polished using nonaqueous media. All samples were stored in evacuated desiccators until ready for SEM/EDX analysis.

On all specimens a compact deposit formed on the surface facing the gas stream. A powdery deposit, probably from the fume, formed on the trailing surface. At the boundary between the two, a thicker drip zone formed.

On the specimens exposed to the oxygen rich gas stream the leading surface deposit, which varied with temperature (thickest at $400^{\circ} \mathrm{C}$ ) ranged from $1.7 \mathrm{~mm}$ to $0.8 \mathrm{~mm}$. The trailing surface deposit was fairly uniform at about 0.2 to $0.3 \mathrm{~mm}$, Figures 1,2 and 3.

EDX analysis shows high concentration of potassium with traces of sulfur throughout the bulk of the salt deposit, however, the top layer of the salt deposit is high in sulfur $\left(\mathrm{K}_{2} \mathrm{SO}_{4}\right)$. In previous tests using only $\mathrm{K}_{2} \mathrm{SO}_{4}$, a layered deposit was formed on the specimens. However, with the $\mathrm{K}_{2} \mathrm{CO}_{3} / \mathrm{K}_{2} \mathrm{SO}_{4}$ charge, layering did not occur but small potassium rich nodes were found in a matrix of potassium and sulfur. Figure 4 , specimen temperature $400^{\circ} \mathrm{C}$, shows these small nodes. Again, Figure 5, specimen temperature $500^{\circ} \mathrm{C}$, shows the potassium rich nodular formations. In the $590^{\circ} \mathrm{C}$ sample, Figure 6 , the nodes are not predominant and a more even surface can be observed. An explanation for the difference in the coating would be that two different salts with melting points varying by $178{ }^{\circ} \mathrm{C}$ 
would show areas of incongruent melting. However, at the edge of the coating, it is possible that the hot gas stream volatilized the $\mathrm{K}_{2} \mathrm{CO}_{3}$ leaving behind a greater concentration of sulfur than potassium in the form of $\mathrm{K}_{2} \mathrm{SO}_{4}$.

The corrosion band area on the 304 stainless steel increases with increasing temperature. The variation in corrosion can be observed in the comparison of Figure 7 (specimen temperature $500{ }^{\circ} \mathrm{C}$ ) with Figure 8) specimen temperature $590{ }^{\circ} \mathrm{C}$ ). SEM/EDX analysis of both samples, Figures $7 \mathrm{a}-7 \mathrm{~g}$ and Figures $8 \mathrm{a}-8 \mathrm{j}$, indicate metal corrosion and metal cation migration, however, the $590{ }^{\circ} \mathrm{C}$ specimen shows the corrosion picture more vividly.

SEM/EDX analysis seems to indicate that preferential leaching of the metal cations from the bulk material (304 stainless steel) is found in a somewhat orderly fashion. The analysis shows that, moving from the stainless steel bulk material to the salt deposit, a high chrome concentration area is found along the edge of the tube and below the surface of the tube top. Areas of high nickel concentration are found within the high chrome concentration matrix while areas of high iron concentration are found next to the salt. Figures 9a-9f show that the iron is found in areas of high potassium concentration a good distance away from the reaction interface region of the stainless steel/salt deposit. Figures $10 a-10 c$ again show iron well away from the reaction zone.

In a fuel rich hot gas stream, a thin, 0.6 to $0.8 \mathrm{~mm}$, as compared to the oxygen rich environment, salt deposit was formed. As noted in the oxygen rich series these samples also exhibited decreasing thickness with increasing temperature. In contrast to the oxygen rich specimen the fume deposit, 0.4 to $0.7 \mathrm{~mm}$ (the layer on the under side of the tube), was heavier. However, it also decreased with temperature, Figures 11, 12 and 13.

As in the oxygen rich test samples the fuel rich samples also exhibited reaction zone areas. Again, these areas showed increased activity in corrosion with increased sample temperature. Figure 14, specimen temperature $500{ }^{\circ} \mathrm{C}$ and Figure 15 , specimen temperature $590{ }^{\circ} \mathrm{C}$ show areas of corrosion at the stainless steel/salt interface with areas of high metal cation concentration. However, the reaction areas do not seem to be as great under the fuel rich conditions as compared to the oxygen rich conditions.

As noted by SEM/EDX analysis, Figures $14 \mathrm{a}-14 \mathrm{~g}$ and Figures $15 \mathrm{a}-15 \mathrm{~g}$, the edge of the stainless steel bulk material contains regions of high chrome concentration followed by areas of high nickel concentration. Areas of high iron concentration are found next, with iron and potassium in the salt deposit adjacent to the stainless steel. The salt deposit seems to contain more sulfur than in the oxygen rich cases, but both have a crust of potassium and sulfur in high concentration on the top of the salt layer. 
Both systems, oxygen rich and fuel rich, show evidence of metal corrosion. However, the fuel rich system seems to show less evidence of damage to the bulk stainless steel. Both system also seems to indicate the same metal cation movement from the bulk stainless steel towards the salt deposit.

Stainless Steel Reference Specimen - As with most analytical techniques, reference samples are used to check some stage of the analysis. At the present time a randomly selected sample type 304 stainless steel that has been cleaned, cut and polished has been used to check outer edges or surfaces for areas where corrosion would most likely occur. A general overview of the tube (Figure 16) would seem to indicate that the 304 stainless is very clean and uniform on the outer edges. However, Figures 17 and 18, shows that in the manufacturing, rough surfaces, i.e., holes and pit areas, can occur. These areas would be more susceptible to a corrosion process and promote deterioration of the surface under hot plasma and seeding conditions. Therefore, not all areas analyzed for pits and holes are necessarily due to the corrosion process. EDX analysis shows that traces of sulfur are already present in the matrix. No other inconsistences such as areas of high chrome concentration or high iron concentration are found in the metal, but rather a uniform distribution of chrome, iron and nickel is found throughout the 304 stainless steel.

Plans: Specimens of type 304 stainless steel will be evaluated at 100 hours exposure to a hot gas atmosphere, fuel rich and oxygen rich, with seeding of a salt every 24 hours. Samples will then be analyzed using SEM/EDX to establish corrosion and leaching of metal cations.

A program will be initiated using type 316 stainless steel tubular specimens under the same general conditions that have been established in running the type 304 stainless steel samples. 


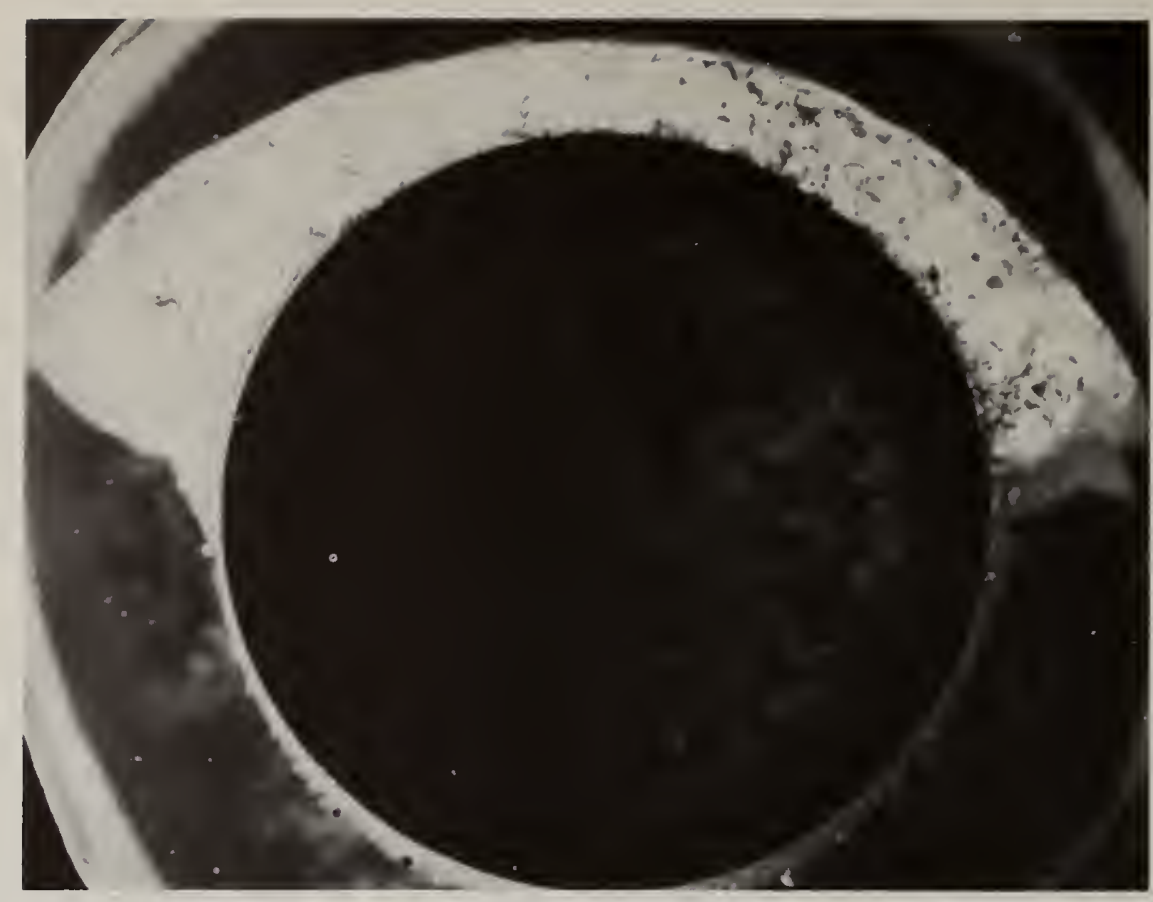

Fig. 1. Section of Type 304 stainless steel tubing after exposure to $\mathrm{K}_{2} \mathrm{CO}_{3} / \mathrm{K}_{2} \mathrm{SO}_{4}$ seeded oxygen rich hot gas stream. Note formation of thick deposit, $1.7 \mathrm{~mm}$, on upper surface and thin powdary deposit on lower surface. Tube temperature $400^{\circ} \mathrm{C} .6 \mathrm{X}$.

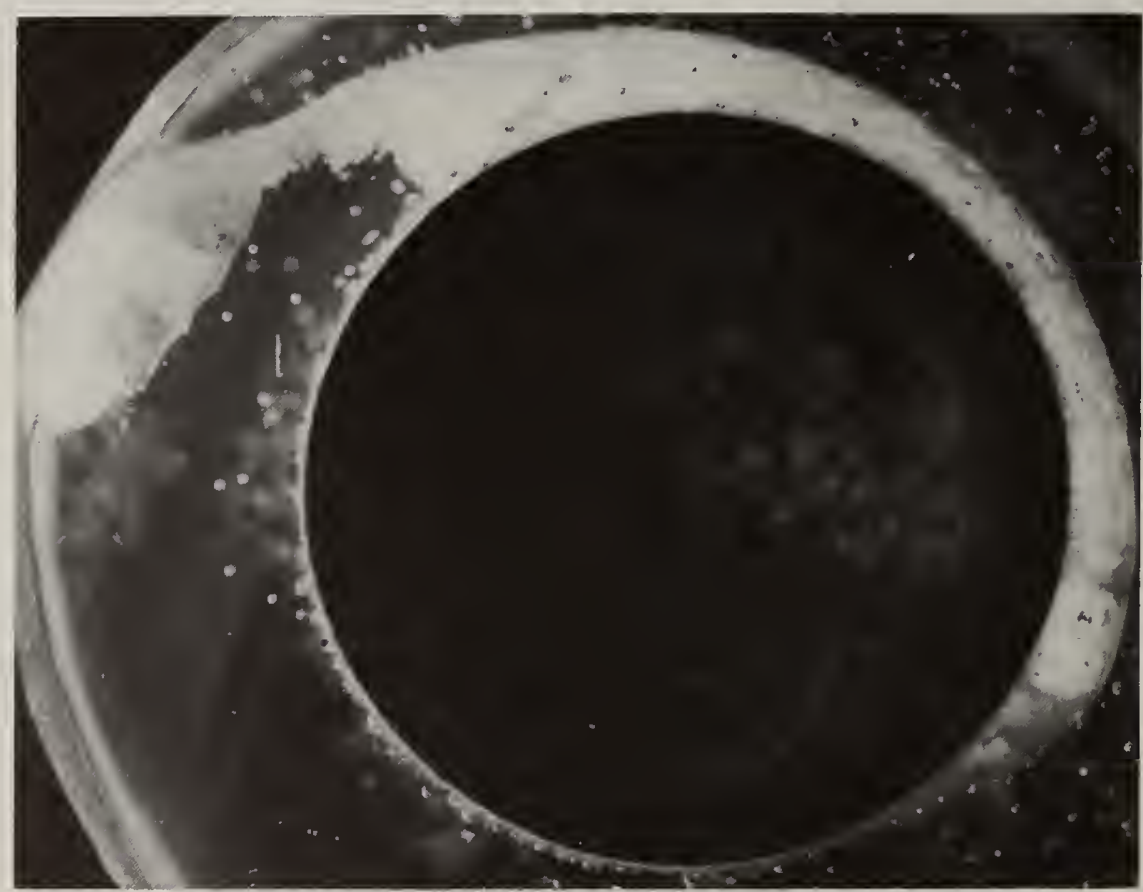

Fig. 2. Section of Type 304 stainless steel tubing after exposure to $\mathrm{K}_{2} \mathrm{CO}_{3} / \mathrm{K}_{2} \mathrm{SO}_{4}$ seeded oxygen rich hot gas stream. Note formation of thick deposit, $1 \mathrm{~mm}$ on upper surface. Tube temperature $500^{\circ} \mathrm{C} .6 \mathrm{X}$. 


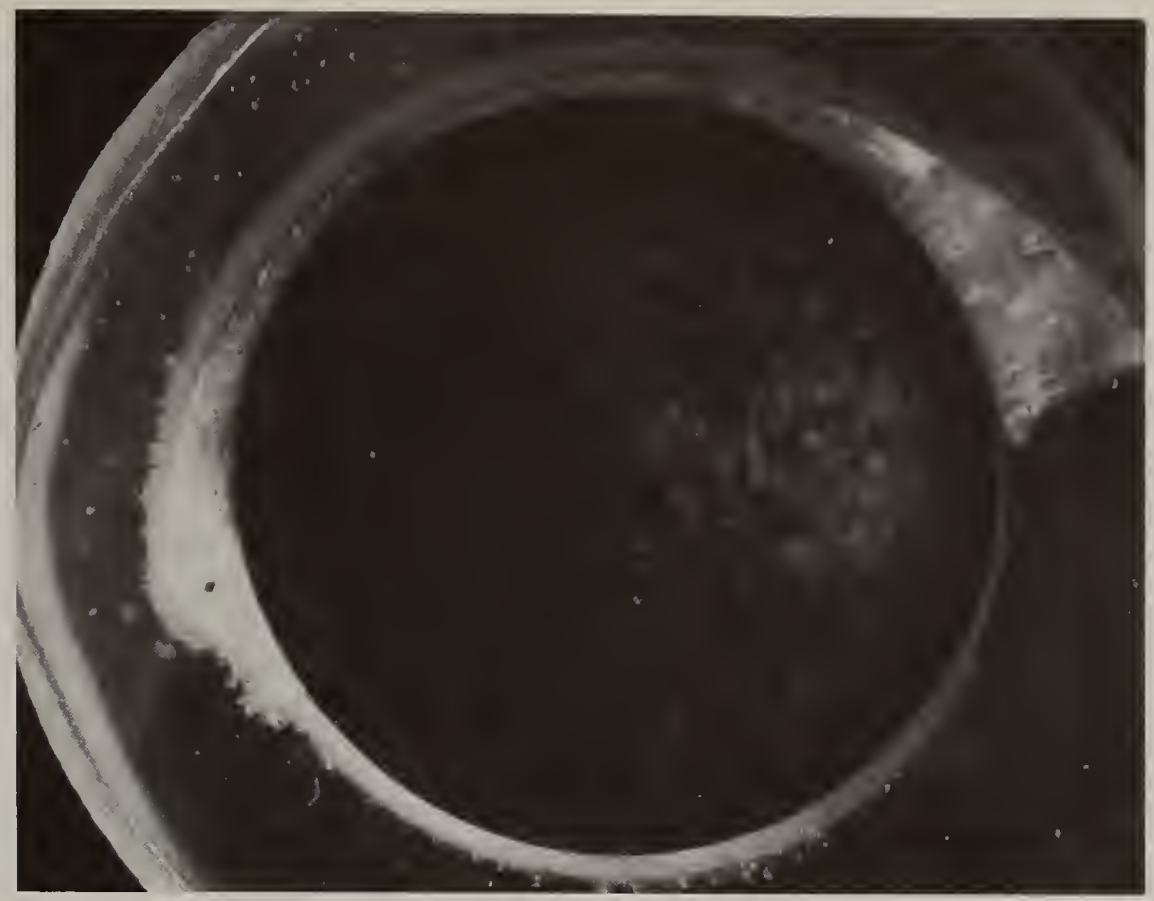

Fig. 3. Section of Type 304 stainless steel tubing after exposure to $\mathrm{K}_{2} \mathrm{CO}_{3} / \mathrm{K}_{2} \mathrm{SO}_{4}$ seeded oxygen rich hot gas stream. Note formation of thinner deposit on upper surface. Tube temperature $590^{\circ} \mathrm{C} .6 \mathrm{X}$.

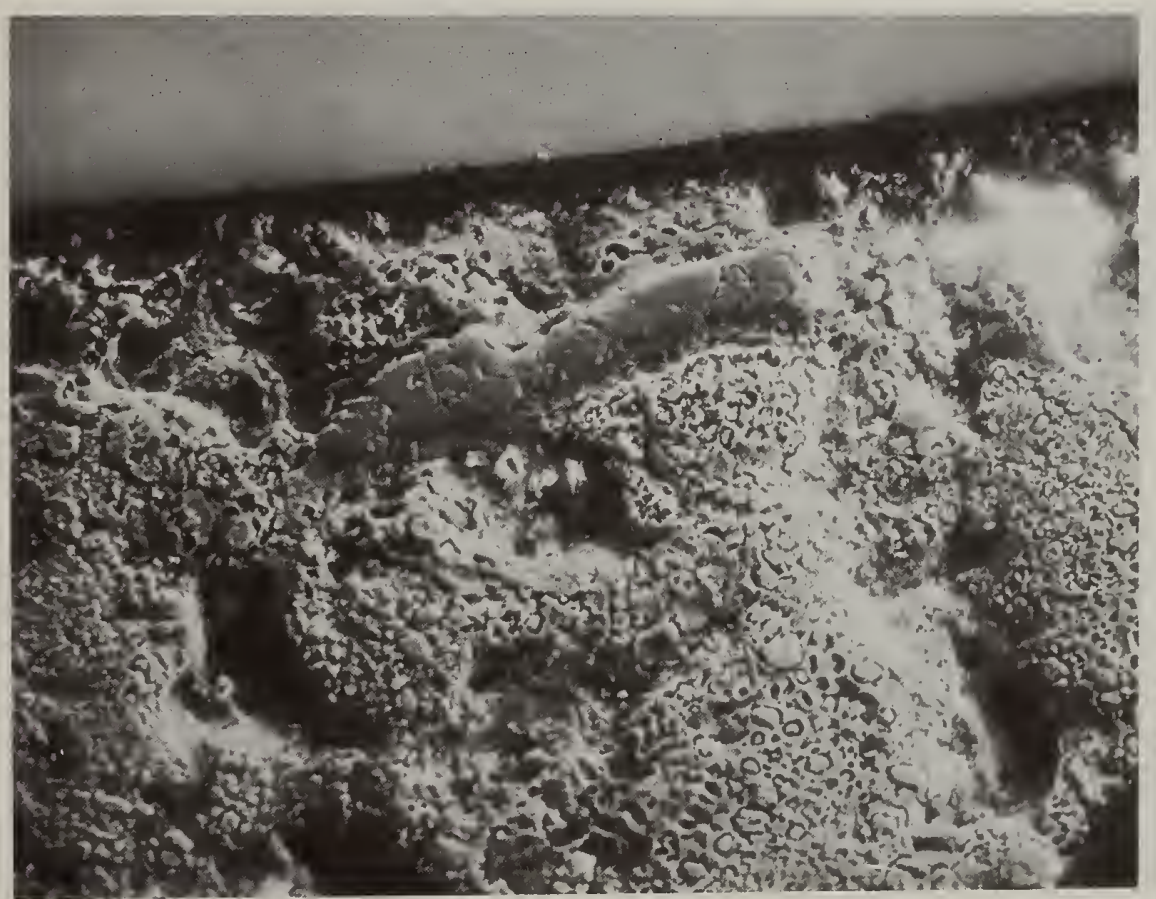

Fig. 4. SEM micrograph, $200 \mathrm{X}$, of small, high potassium concentration nodes in the salt deposit. Specimen temperature $400^{\circ} \mathrm{C}$; gas stream oxygen rich. 


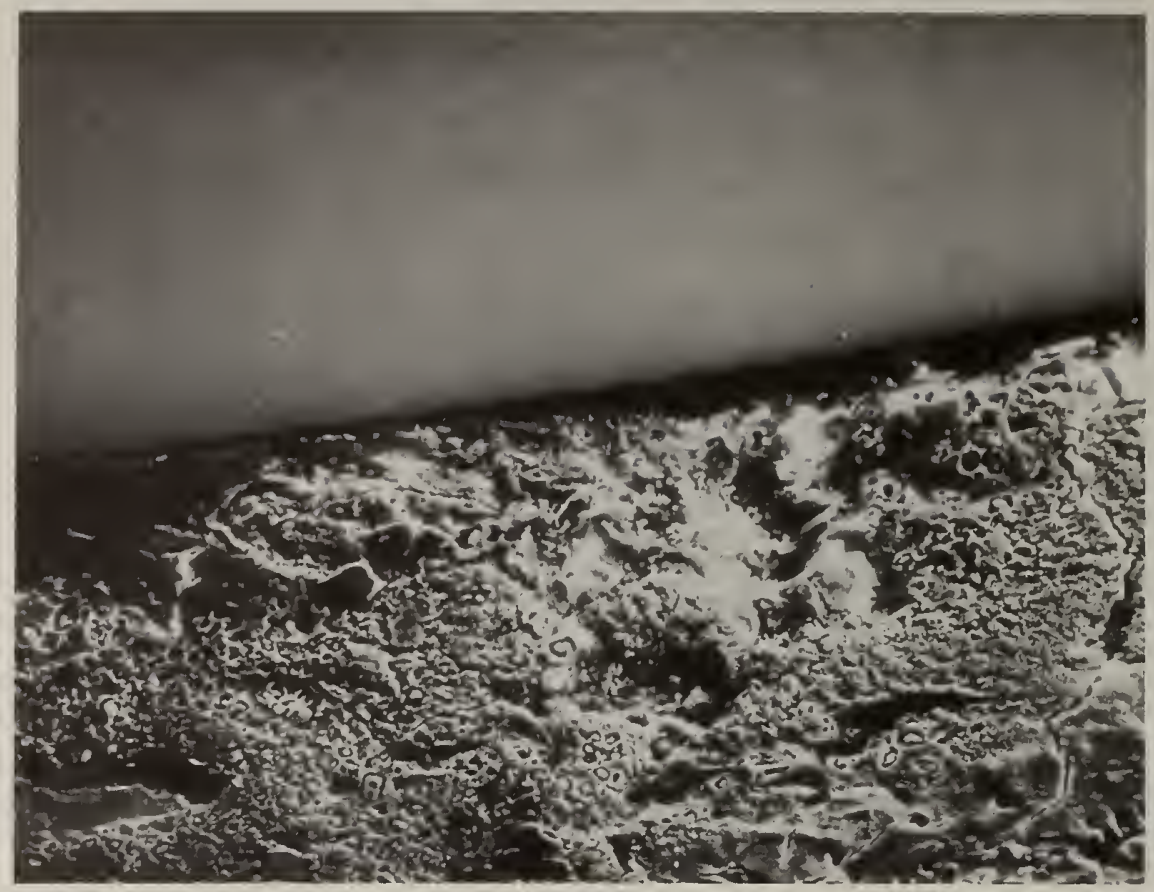

Fig. 5. SEM micrograph, $200 \mathrm{X}$, of sma 11, high potassium concentration nodes in the salt deposit. Specimen temperature $500^{\circ} \mathrm{C}$; gas stream oxygen rich.

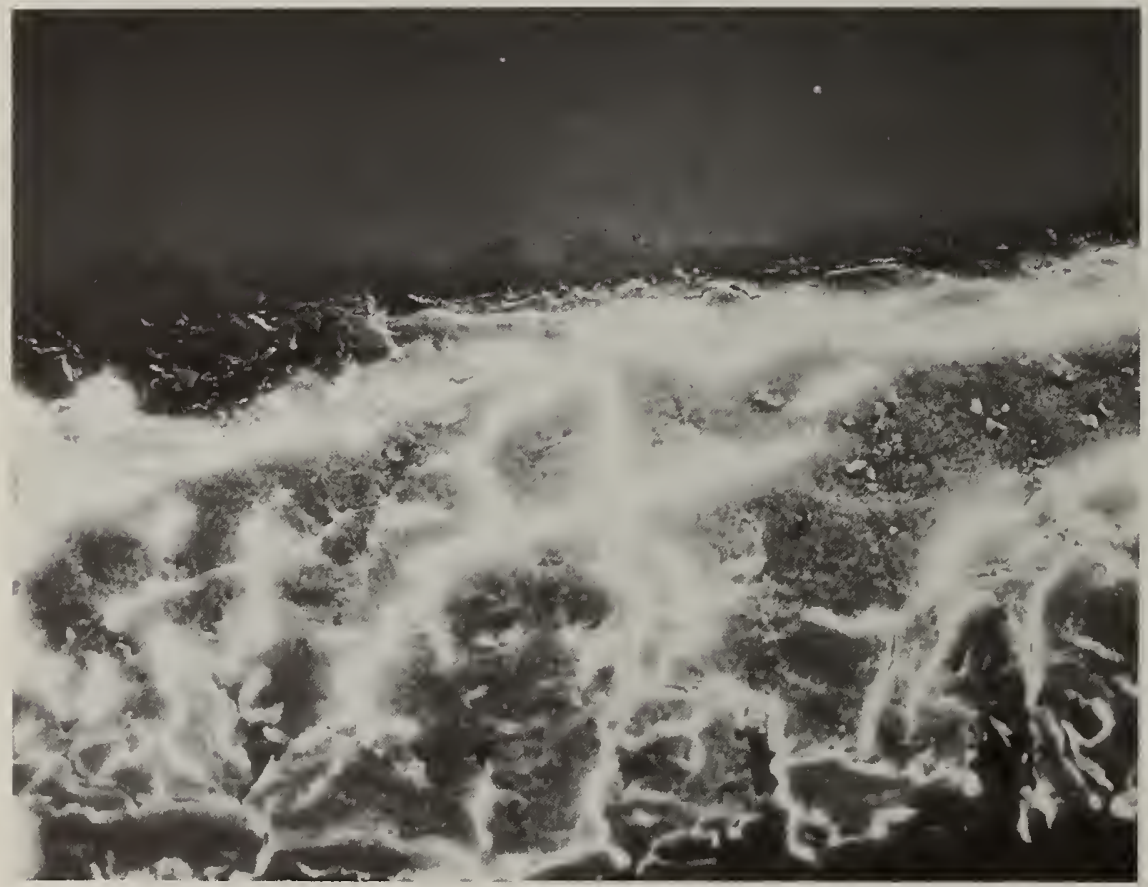

Fig. 6. SEM micrograph, $200 \mathrm{X}$, of salt deposit showing absence of high potassium concentration nodules. Specimen temperature $590^{\circ} \mathrm{C}$; gas stream oxygen rich. 


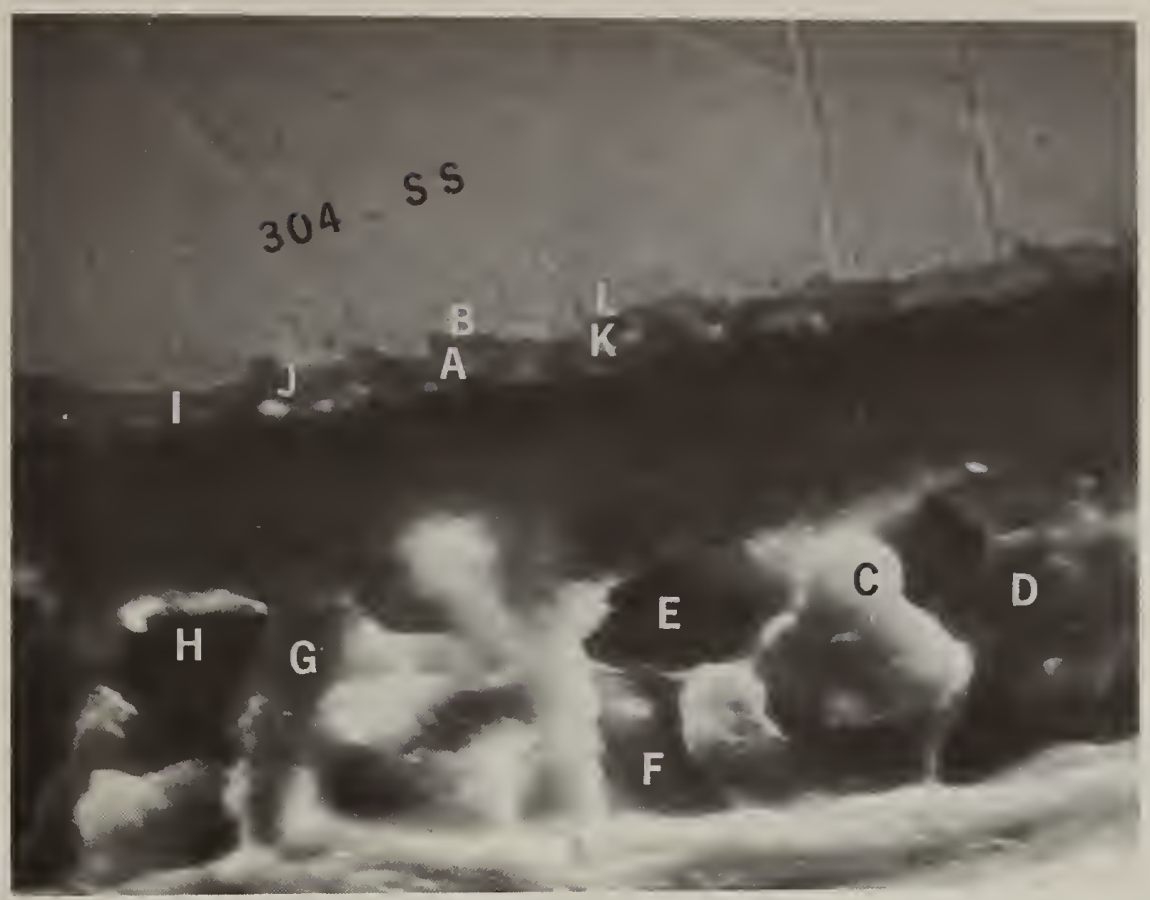

Fig. 7. SEM micrograph, $2000 \mathrm{X}$, of stainless steel-salt deposit reaction zone. Lettered regions correspond to labeled EDX spectra, figures $7 a$ through $7 \mathrm{f}$. Specimen temperature $500^{\circ} \mathrm{C}$; gas stream oxygen rich.

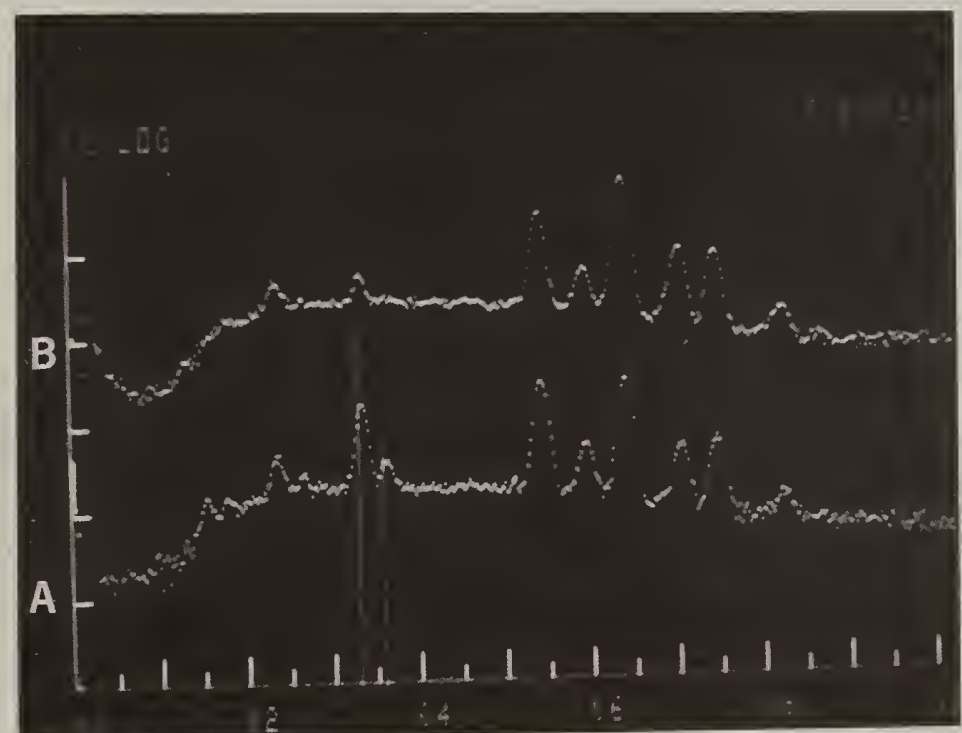

Fig. 7a. EDX spectra of regions $\mathrm{A}$ and $\mathrm{B}$ of figure 7 showing high $\mathrm{Cr}$ concentration area. 


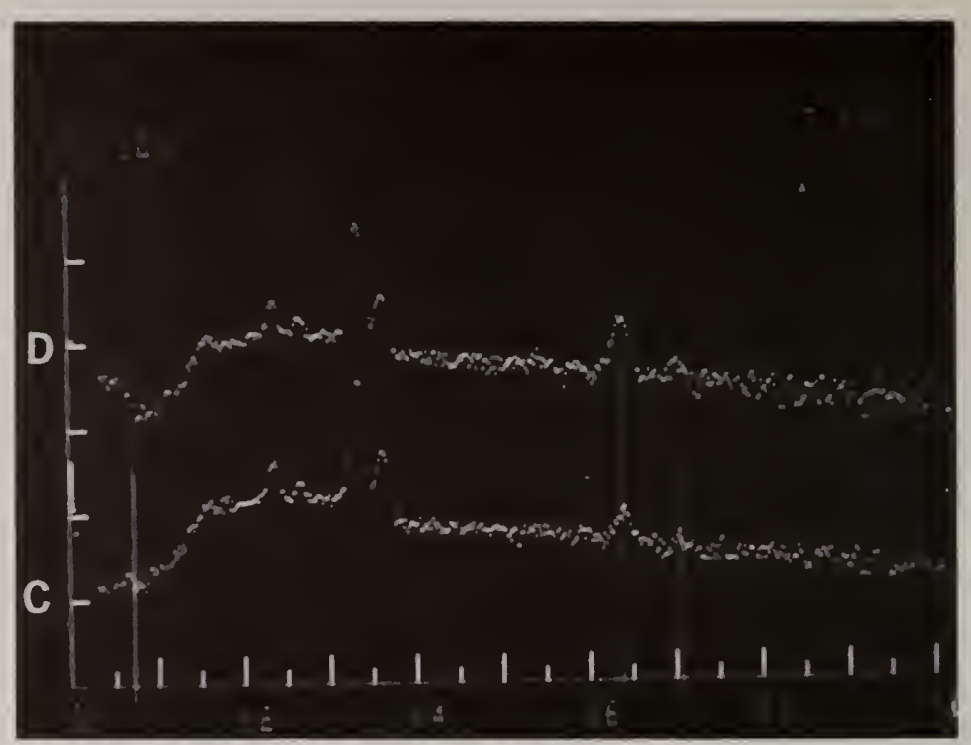

Fig. 7b. EDX spectra of regions C and D of Fig. 7 showing region of high potassium concentration associated with $\mathrm{Fe}$ in the salt region of the corrosion area.

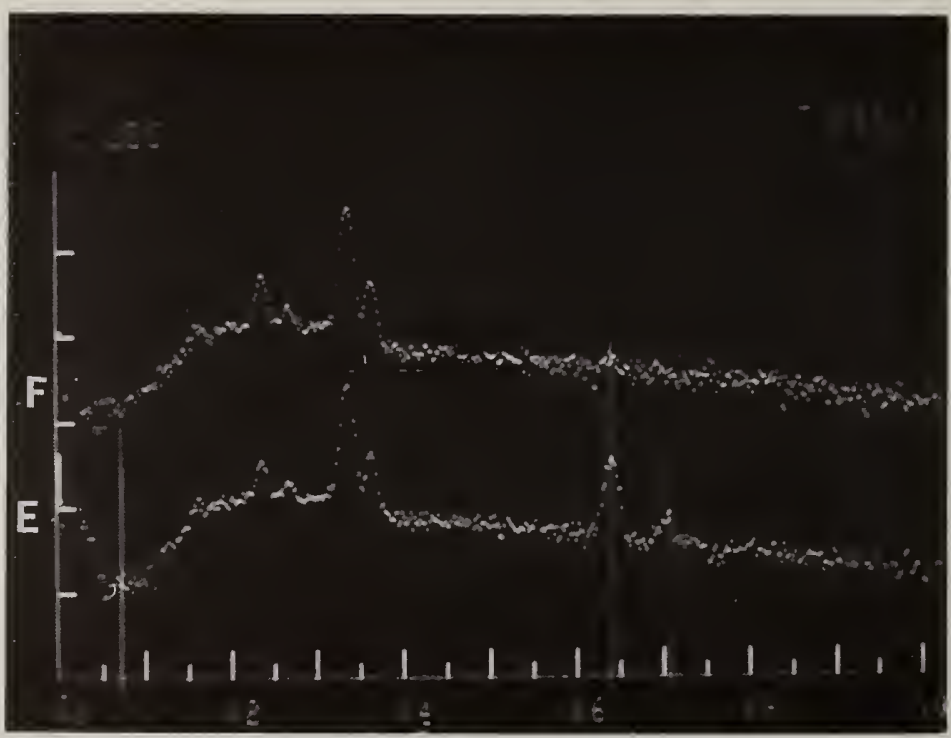

Fig. 7c. EDX spectra of regions $E$ and $F$ of Fig. 7 showing Fe penetration in the salt. 


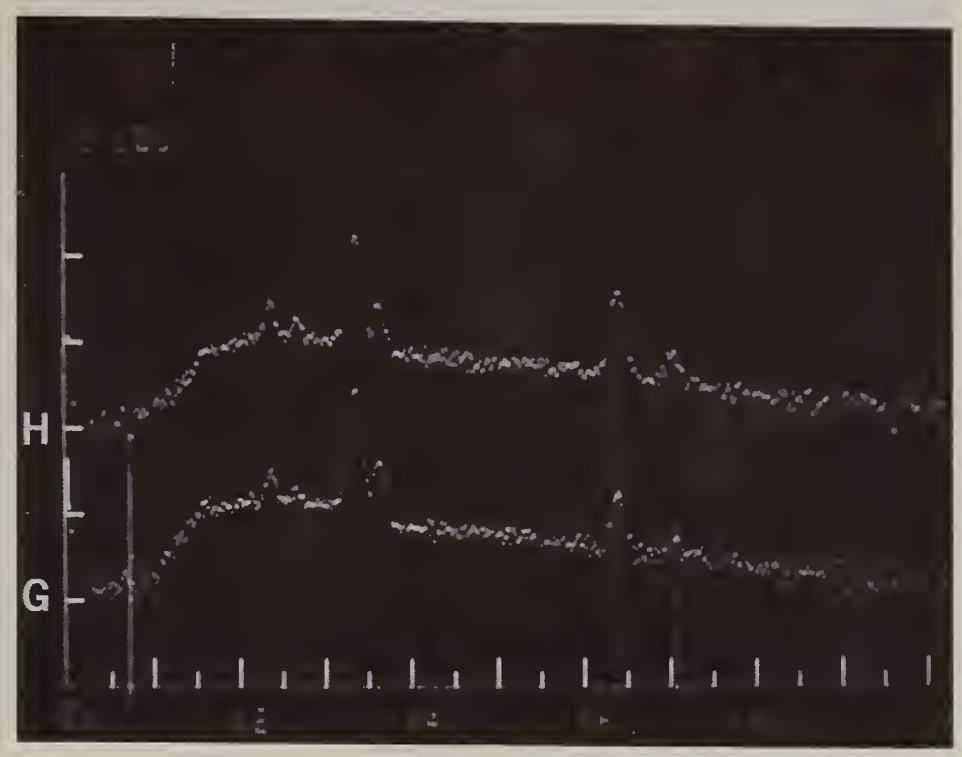

Fig. 7d. EDX spectra of regions $G$ and $H$ of Fig. 7 showing Fe penetration in the salt.

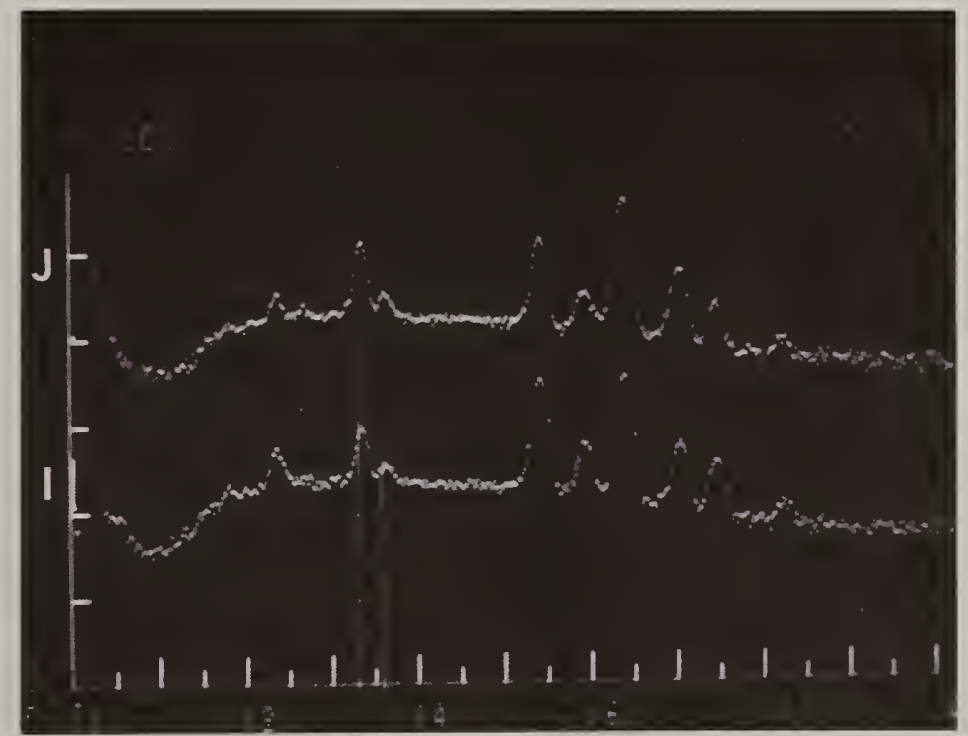

Fig. 7e. EDX spectra of regions $\mathrm{I}$ and $\mathrm{J}$ of Fig. 7 showing areas of high $\mathrm{Cr}$ and low $\mathrm{Ni}$ concentration. 


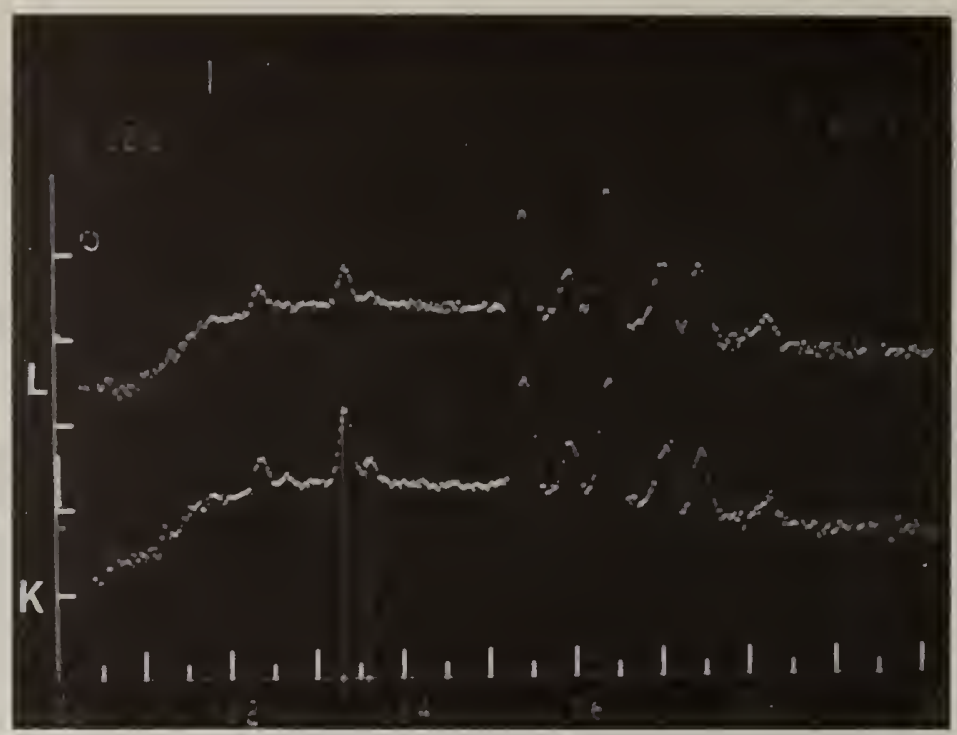

Fig. 7f. EDX spectra of regions $K$ and $L$ of $F i g .7$ showing areas of high $\mathrm{Cr}$ concentration formed on stainless steel edge.

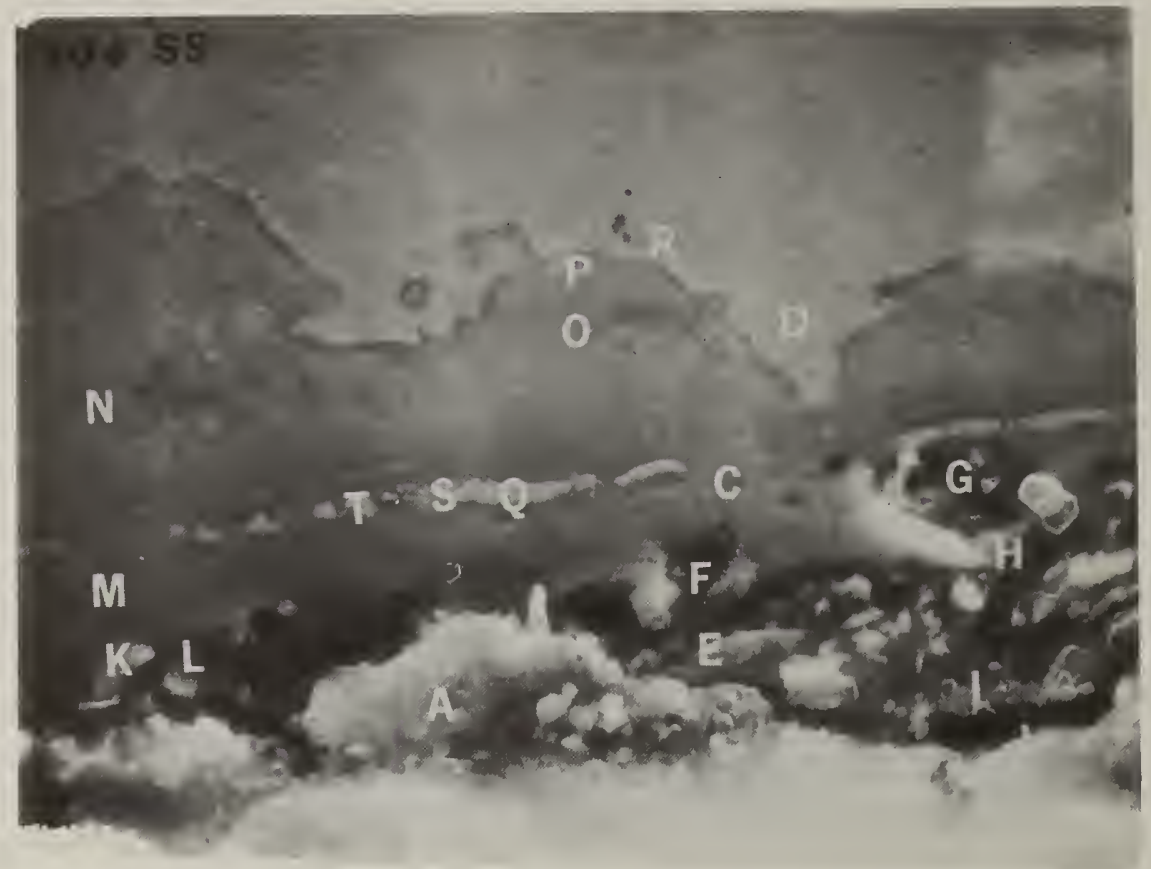

Fig. 8. SEM micrograph, $2000 \mathrm{X}$, of stainless steel-salt deposit reaction zone. Lettered regions correspond to labeled EDX spectra, Figs. 8a-8j. Specimen temperature $590^{\circ} \mathrm{C}$; gas stream oxygen rich. 


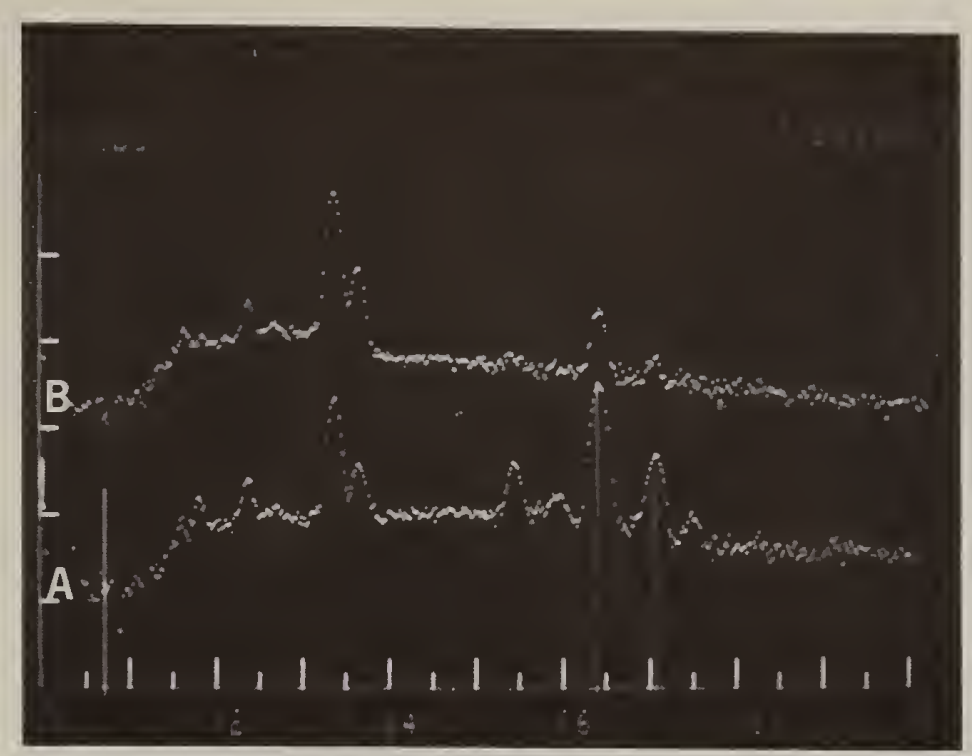

Fig. 8a. EDX spectra of regions $A$ and $B$ of Fig. 8 showing Fe penetration in the salt deposit.

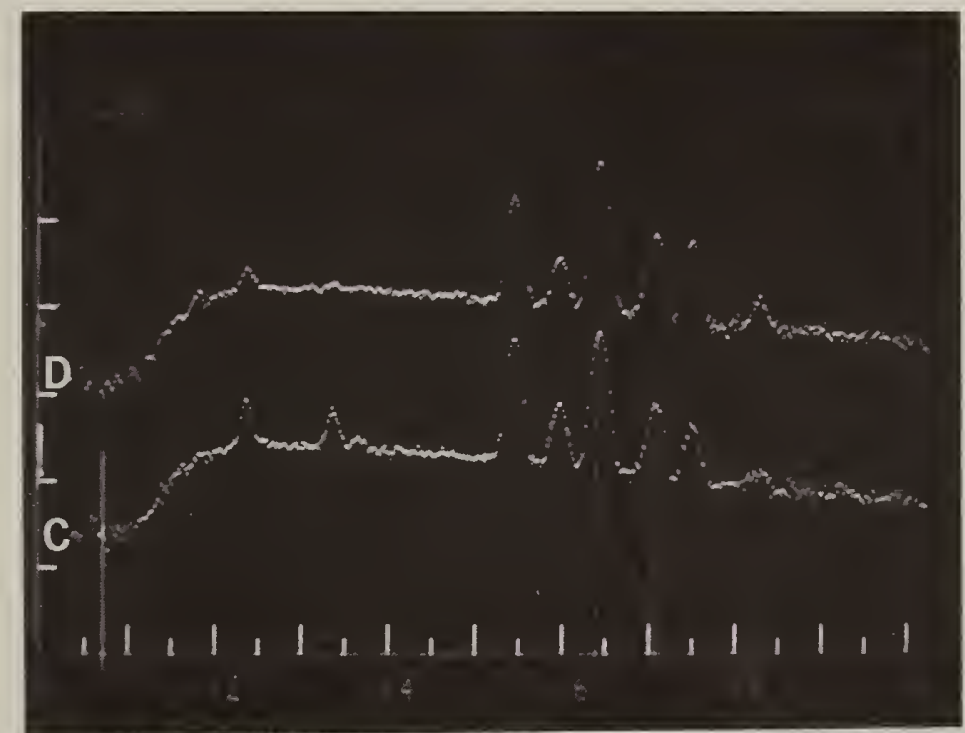

Fig. 8b. EDX spectra of regions C and D of Fig. 8 showing area of high $\mathrm{Cr}$ concentration as compared to bulk stainless. 


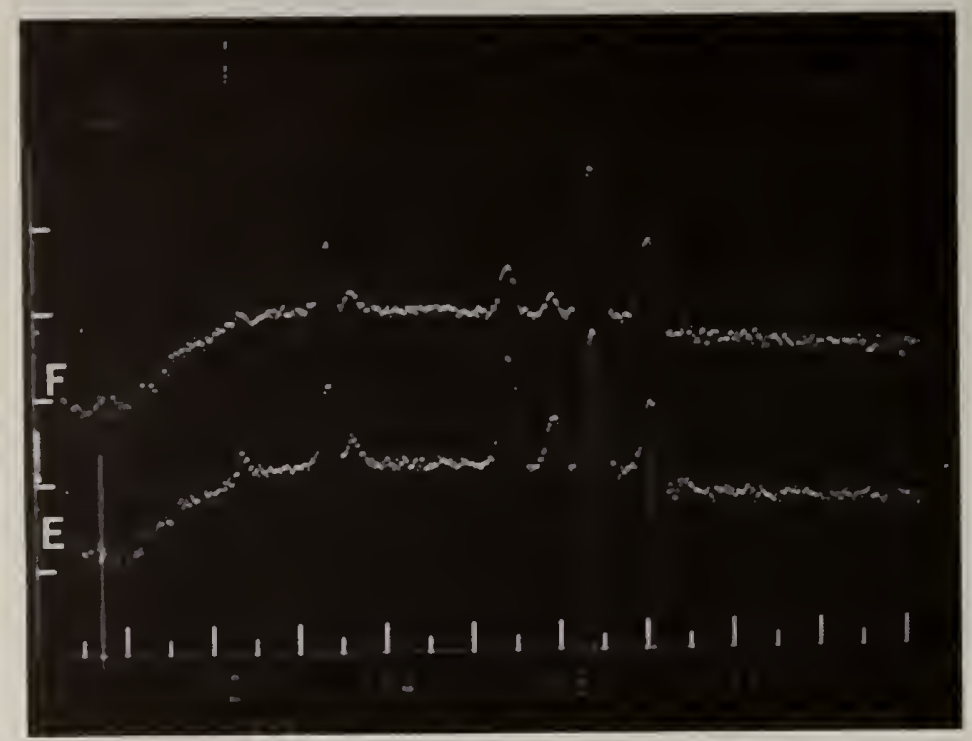

Fig. 8C. EDX spectra of regions $E$ and $F$ of Fig. 8 showing area of high $\mathrm{Cr}$ and high $\mathrm{Fe}$ concentration with absence of $\mathrm{Ni}$ at the stainless steelsalt interface.

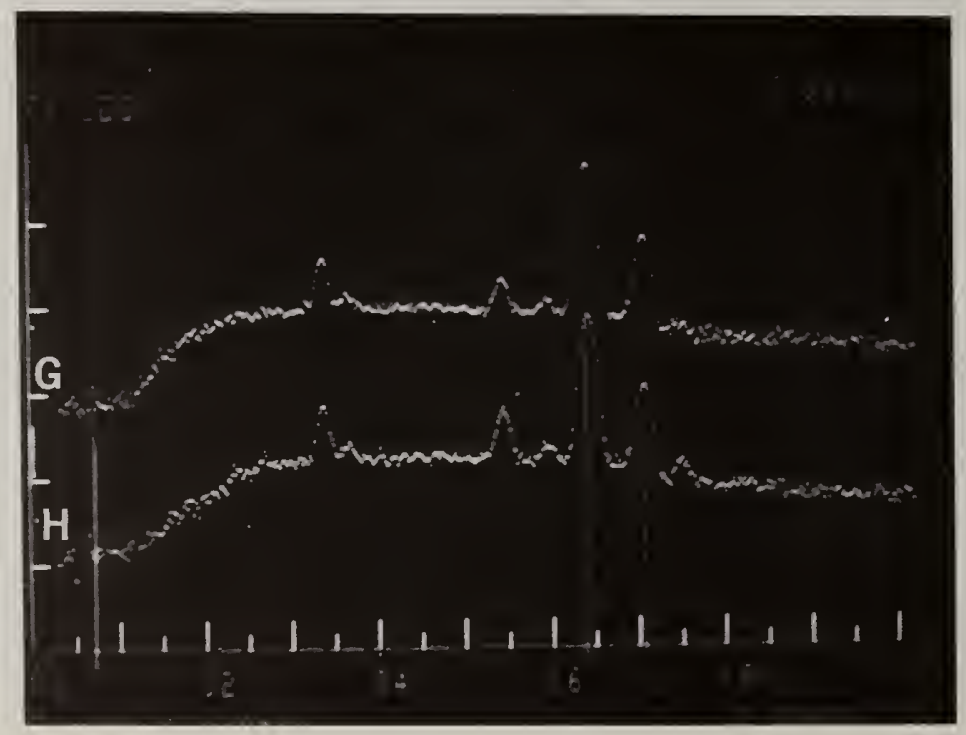

Fig. 8d. EDX spectra of regions $G$ and $H$ of Fig. 8 showing area of high Fe and low $\mathrm{Cr}$ concentration with traces of $\mathrm{Ni}$ at the stainless steel-salt interface. 


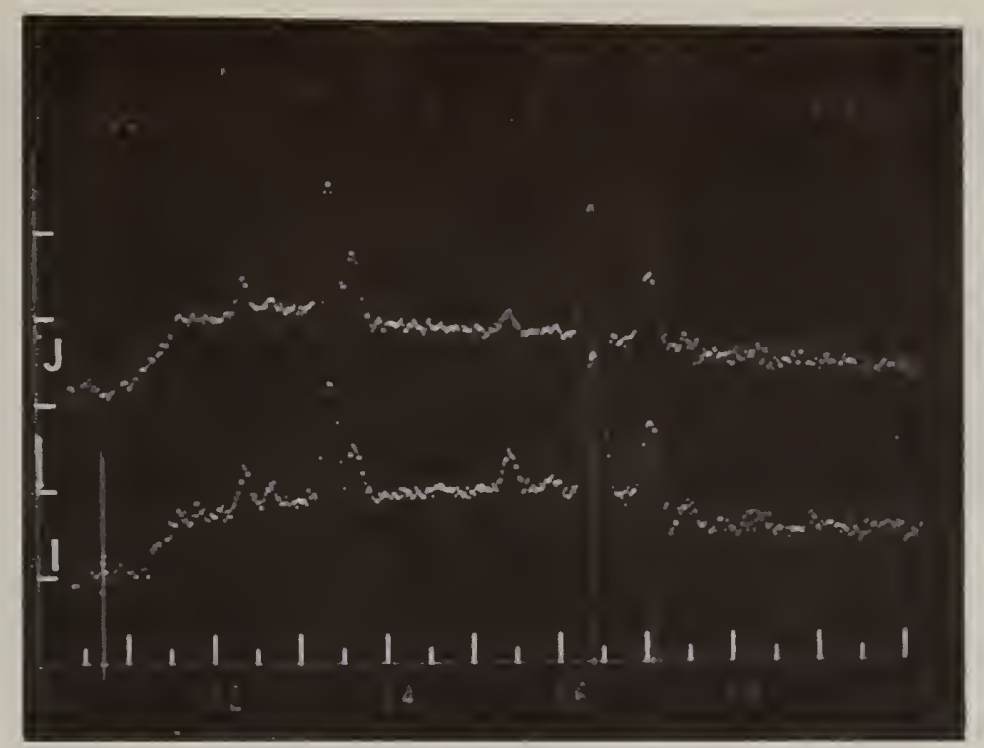

Fig. 8e. EDX spectra of regions I and $J$ of Fig. 8 showing penetration of $\mathrm{Fe}$ and $\mathrm{Cr}$ in the salt deposit.

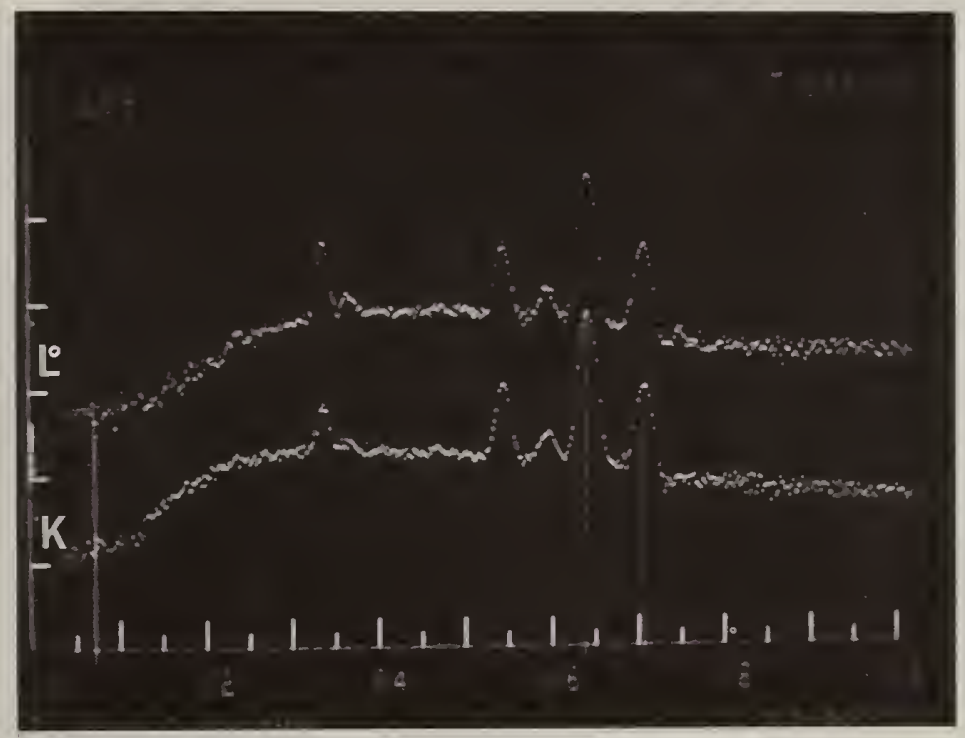

Fig. 8f. EDX spectra of regions $K$ and $L$ of Fig. 8 showing area of high Fe and low $\mathrm{Cr}$ concentration with absence of $\mathrm{Ni}$ at the stainless-steel salt interface. 


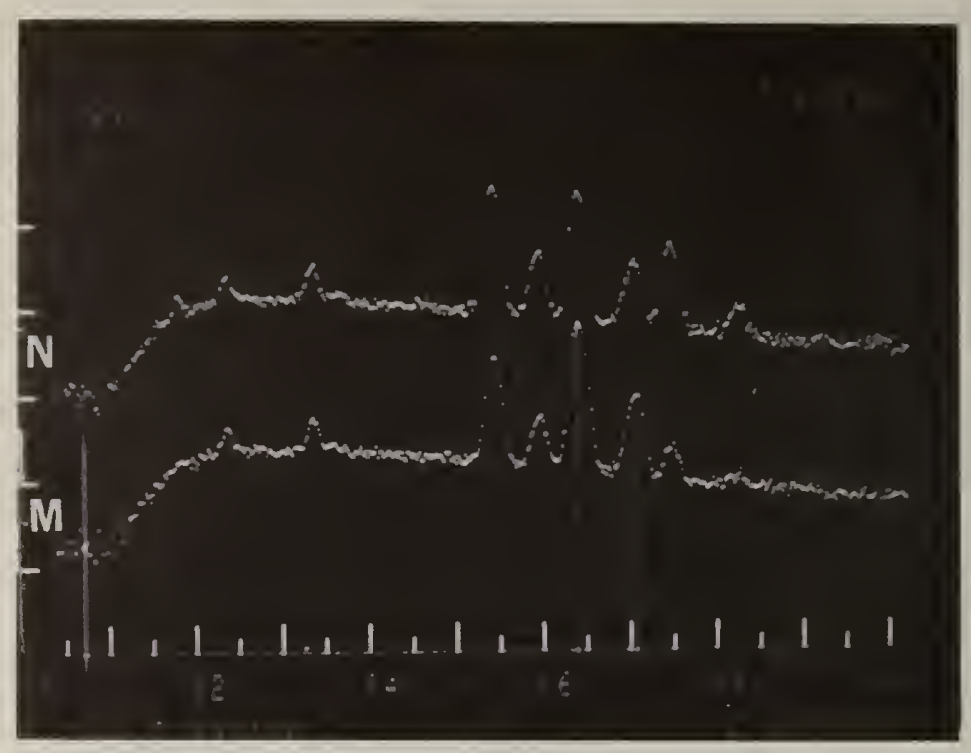

Fig. 8g. EDX spectra of regions $M$ and $N$ of Fig. 8 showing areas of high $\mathrm{Cr}$ and high $\mathrm{Ni}$ concentration as compared to $\mathrm{low} \mathrm{Cr}$ and low $\mathrm{Ni}$ below the stainless steel-salt deposit interface but within the reaction band.

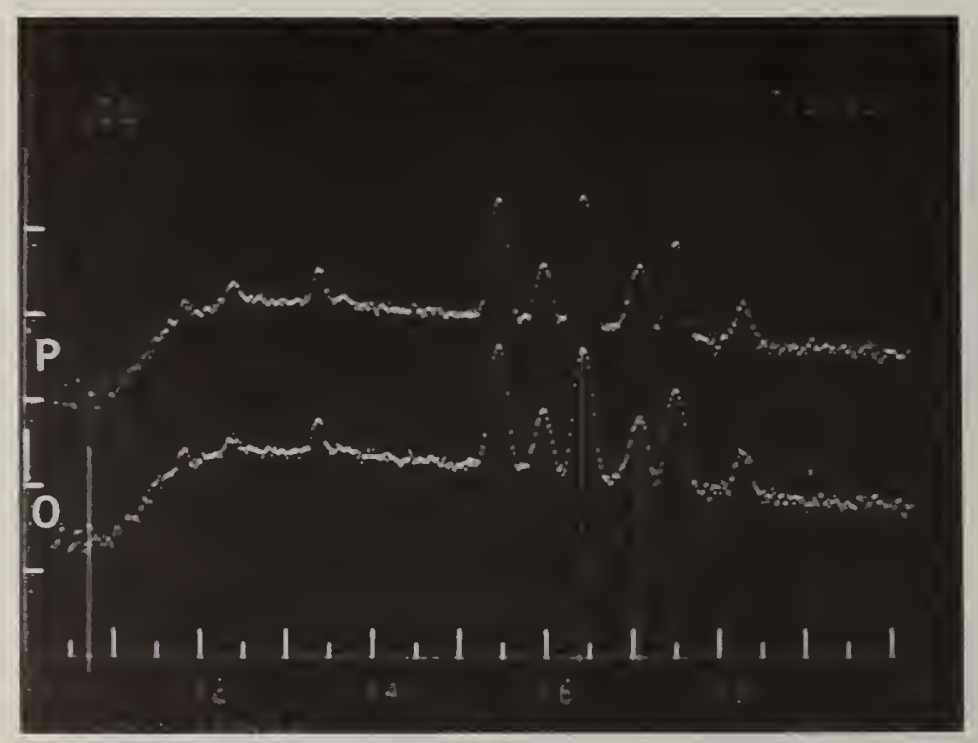

Fig. 8h. EDX spectra of regions 0 and $P$ of Fig. 8 showing areas of high $\mathrm{Cr}$ and high $\mathrm{Ni}$ concentration below the stainless steel-salt deposit interface, but within the reaction band. 


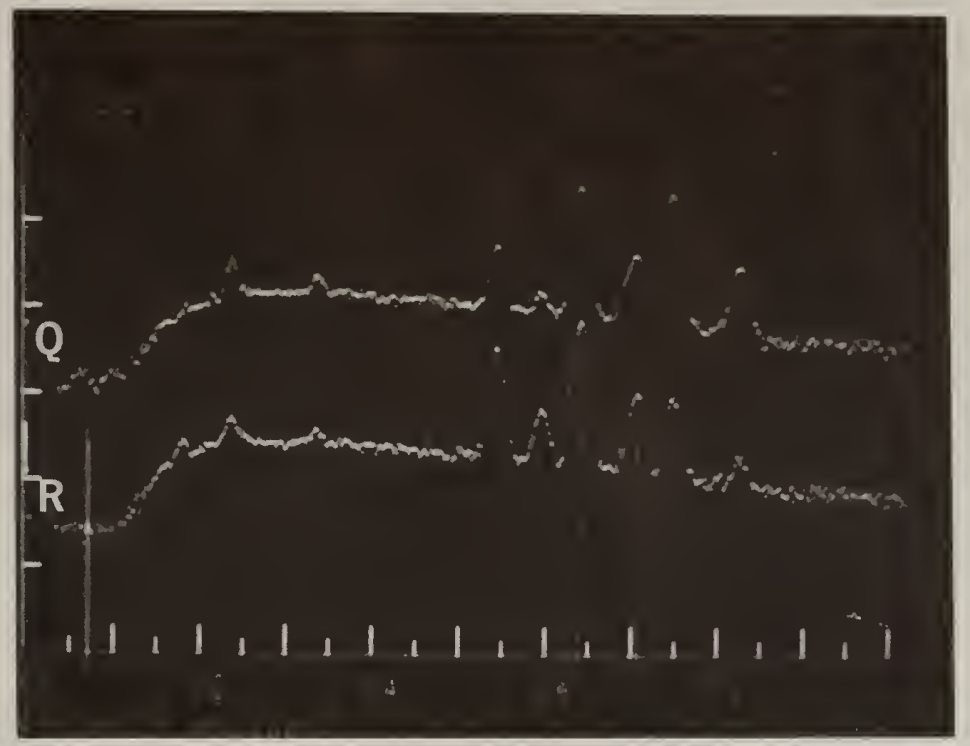

Fig. 8i. EDX spectra of regions $Q$ and $R$ of Fig. 8 indicating a region of very high $\mathrm{Ni}$ concentration in a matrix of high $\mathrm{Cr}$ concentration as compared to the bulk stainless steel.

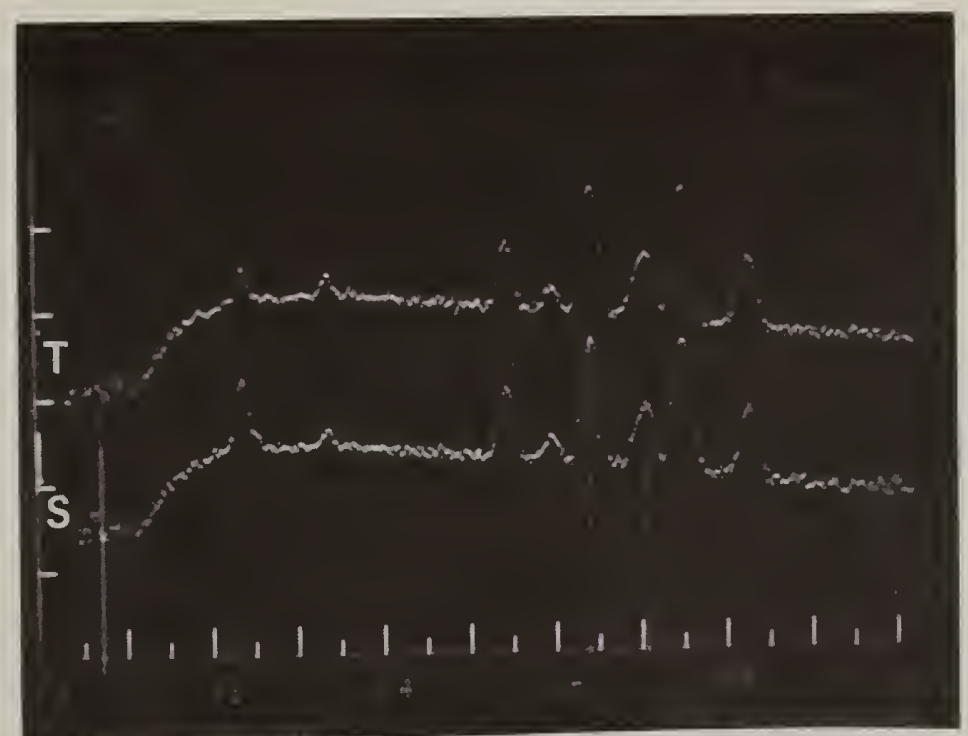

Fig. 8j. EDX spectra of regions $S$ and $T$ of Fig. 8 showing high $N i$ concentration with the high $\mathrm{Cr}$ concentration matrix. 


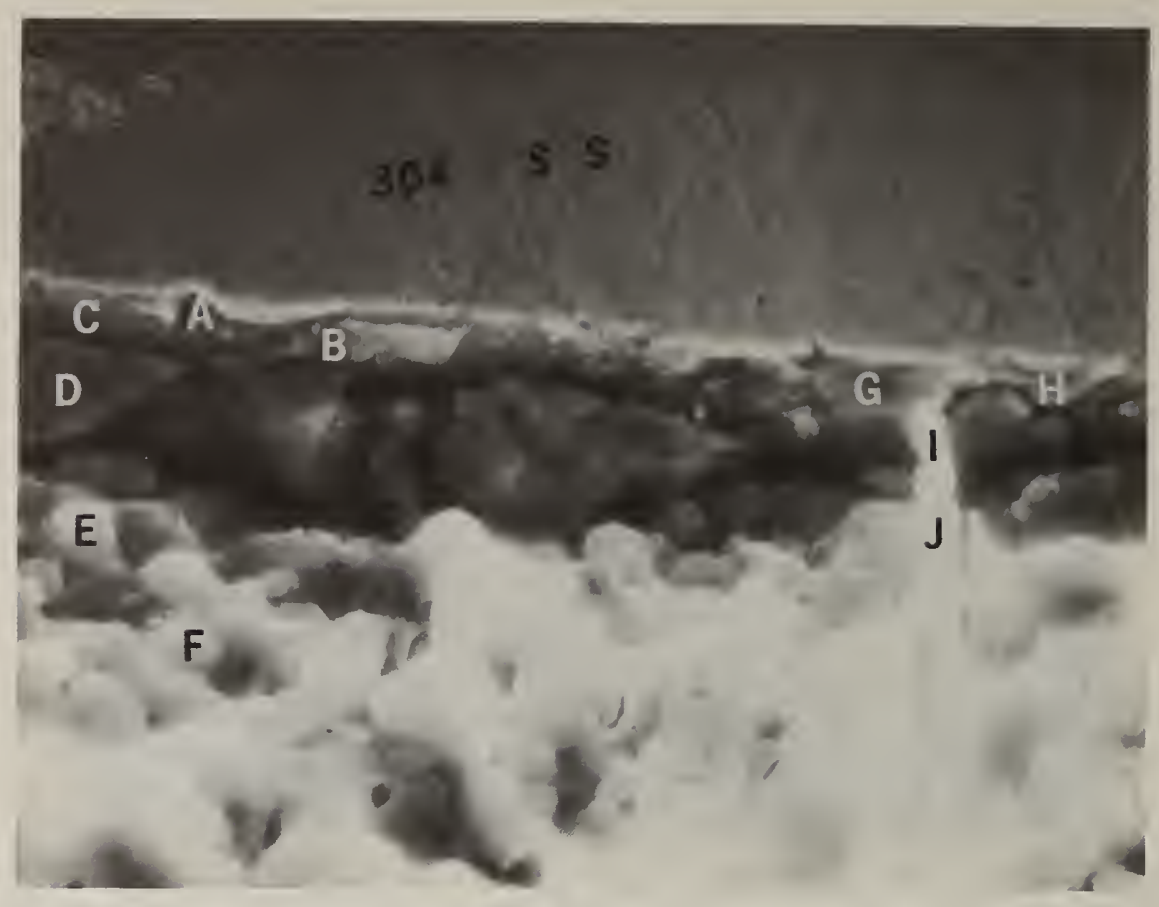

Fig. 9. SEM micrograph, $2000 \mathrm{X}$, of stainless steel-salt deposit reaction zone. Lettered regions correspond to labeled EDX spectra Figs. 9a-9e. Specimen temperature $400^{\circ} \mathrm{C}$; gas stream oxygen rich.

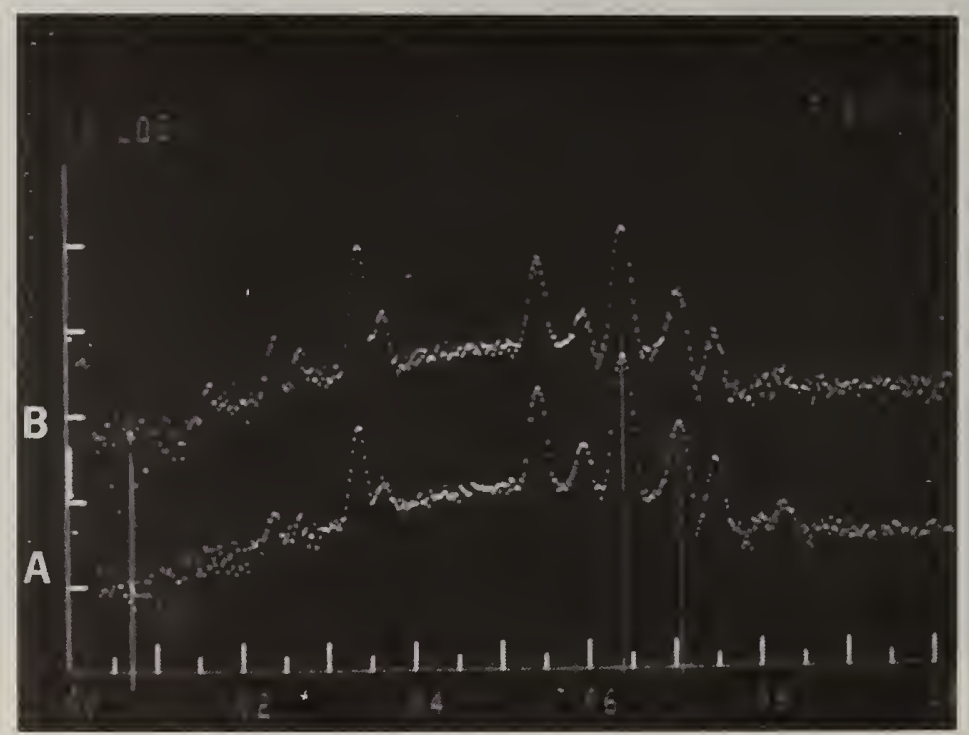

Fig. 9a. EDX spectra of regions A and B of Fig. 9 showing areas of low Ni concentration on the stainless steel interface. 


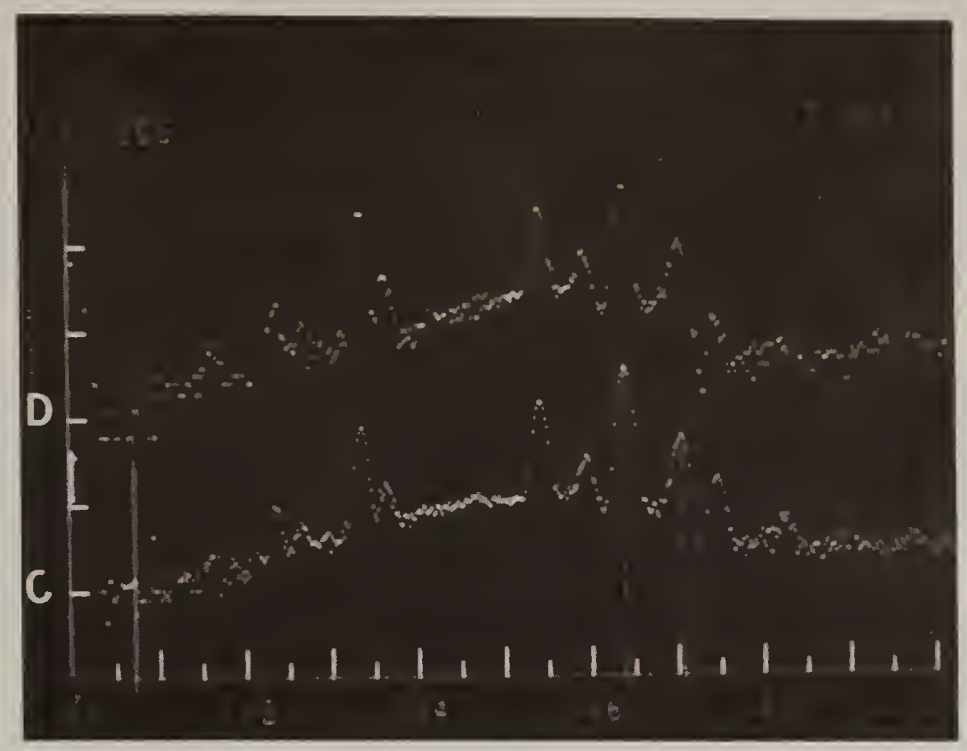

Fig. 9b. EDX spectra of regions C and D of Fig. 9 showing areas of low Ni concentration on the stainless steel interface.

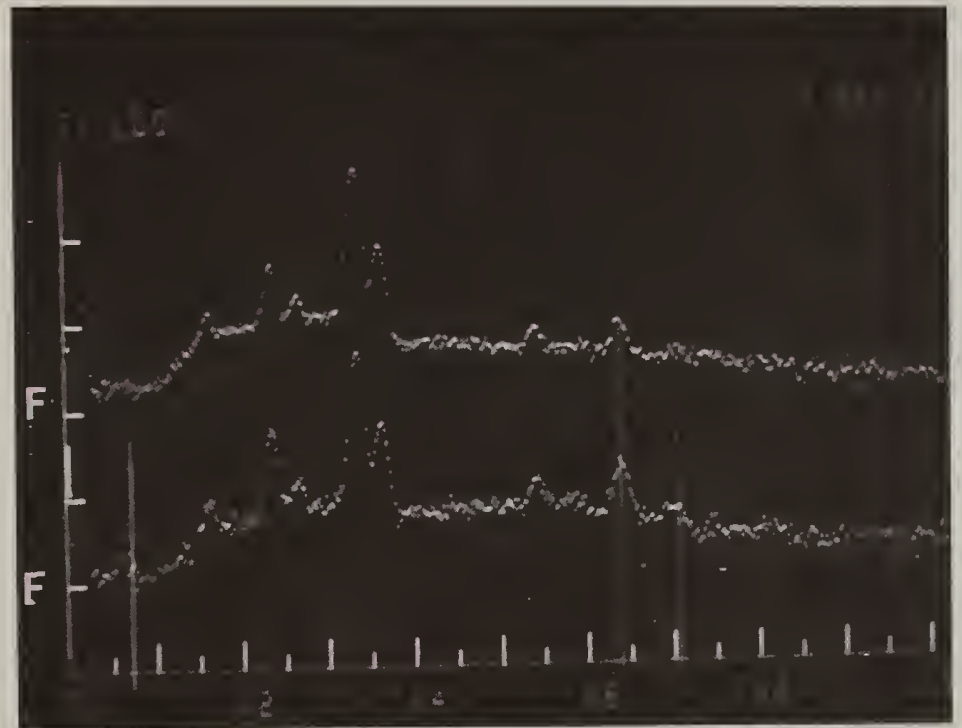

Fig. 9c. EDX spectra of regions $E$ and $F$ of Fig. 9 indicating Fe penetration into the salt deposit. 


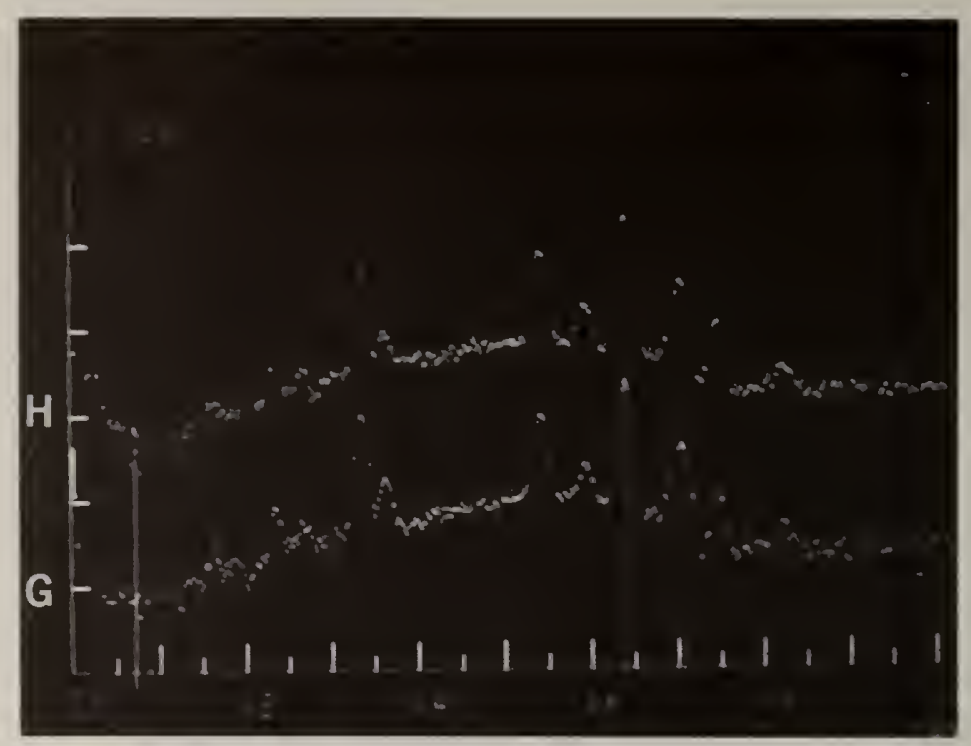

Fig. 9d. EDX spectra of regions $G$ and $H$ of Fig. 9 showing areas of low $\mathrm{Ni}$ concentration on the stainless steel interface.

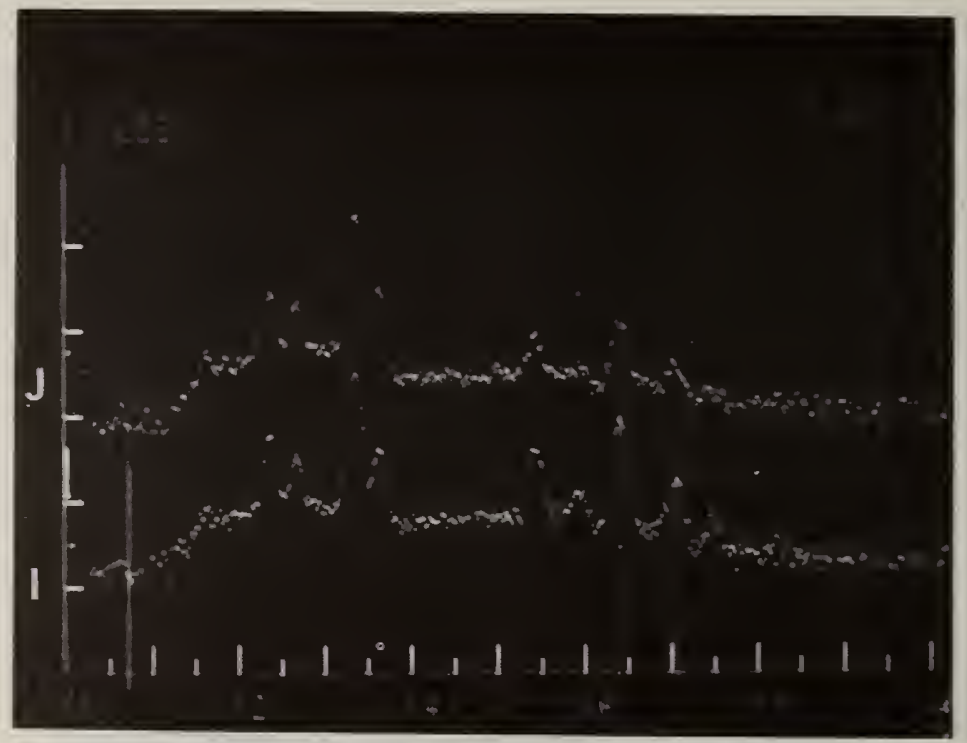

Fig. 9e. EDX spectra of regions I and $\mathrm{J}$ of Fig. 9 indicating $\mathrm{Fe}$ and $\mathrm{Cr}$ penetration into the salt deposit. 


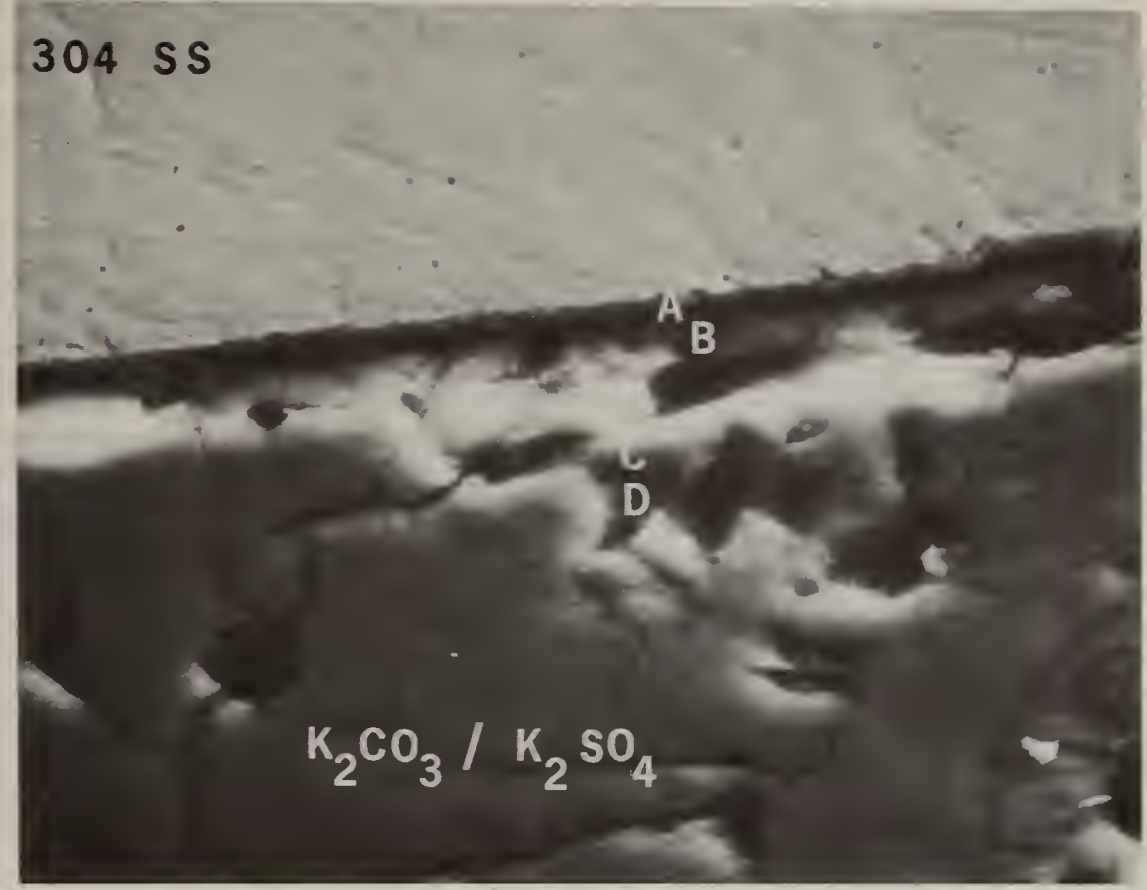

Fig. 10. SEM micrograph, $2000 \mathrm{X}$, of stainless steel-salt deposit reaction zone. Lettered regions correspond to labeled EDX spectra Figs. 10a and 10b. Specimen temperature $400^{\circ} \mathrm{C}$; gas stream oxygen rich.

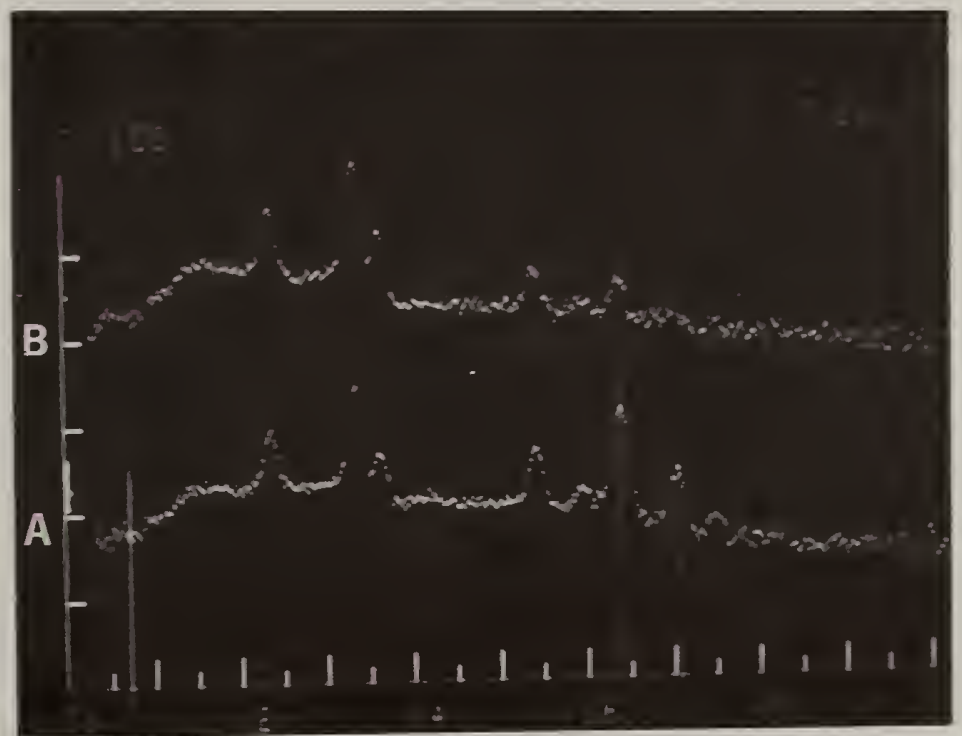

Fig. 10a. EDX spectra of regions $A$ and $B$ of Fig. 10 showing areas of Fe and Cr penetration into an area of potassium and sulfur. 


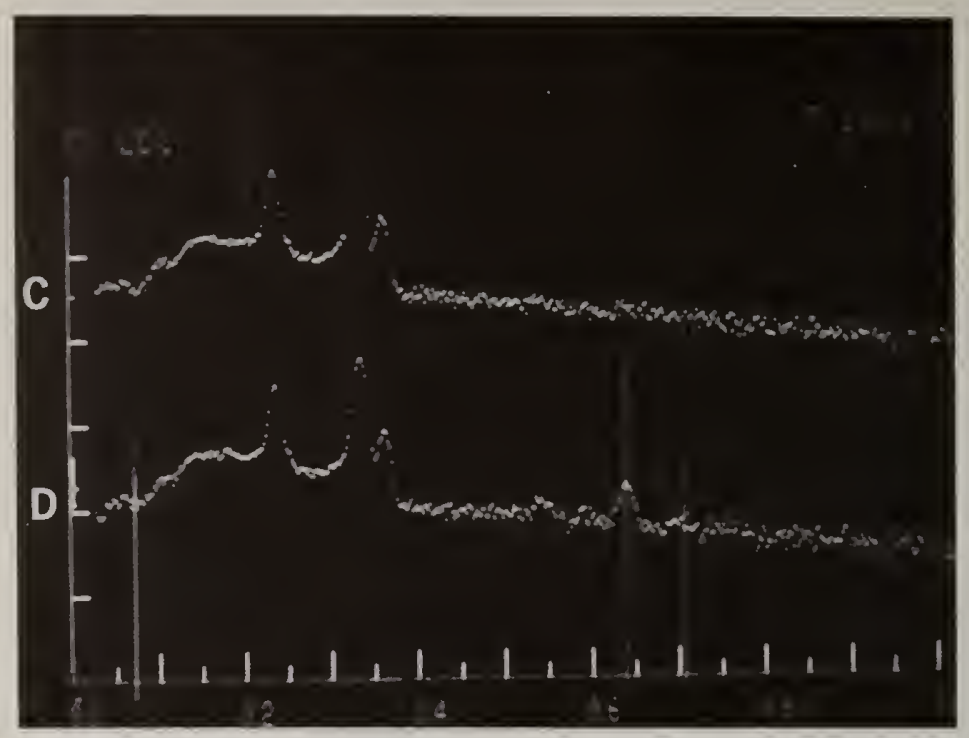

Fig. 10b. EDX spectra of regions C and D of Fig. 10 showing farther penetration of $\mathrm{Fe}$ and $\mathrm{Cr}$ into the salt deposit region.

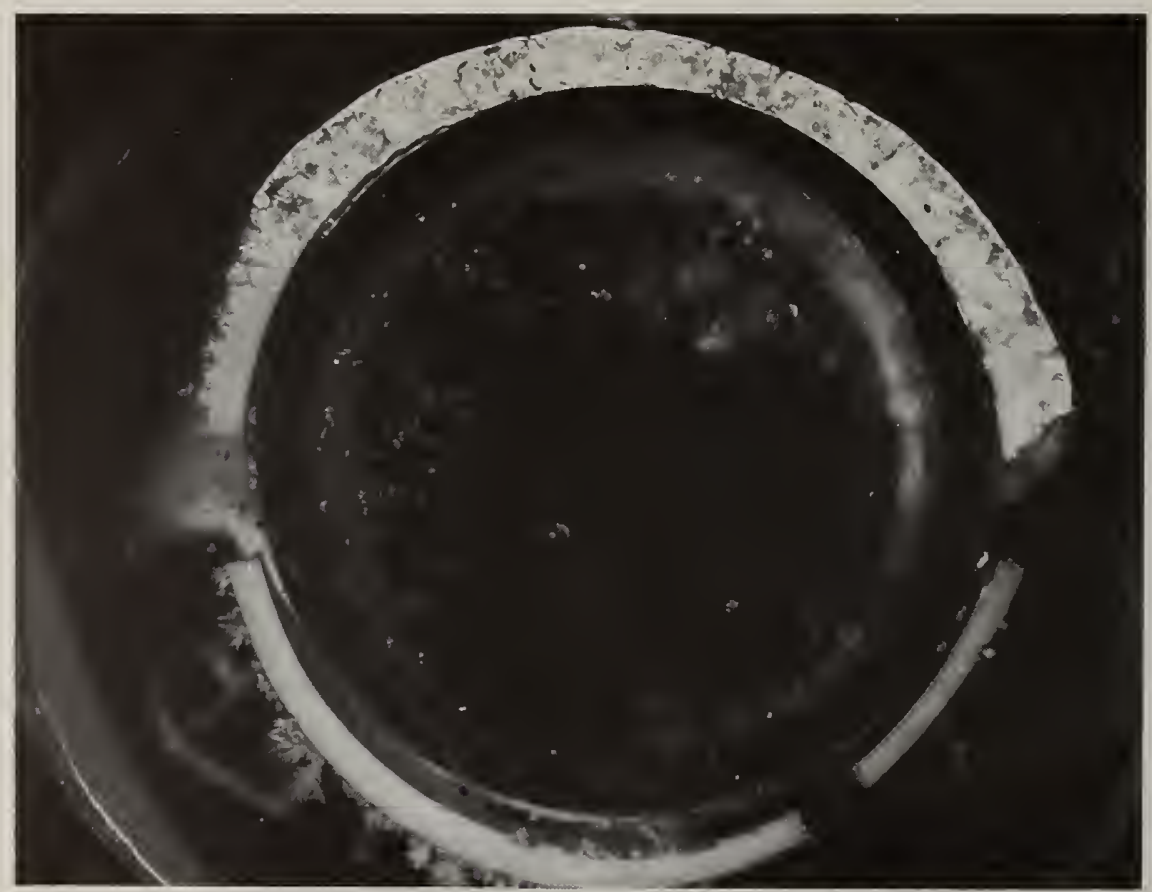

Fig. 11. Section of Type 304 stainless steel tubing after exposure to $\mathrm{K}_{2} \mathrm{CO}_{3} / \mathrm{K}_{2} \mathrm{SO}_{4}$ seeded fuel rich hot gas stream. Note formation of $0.8 \mathrm{~mm}$ deposit on upper surface. Tube temperature $400^{\circ} \mathrm{C} .6 \mathrm{X}$. 


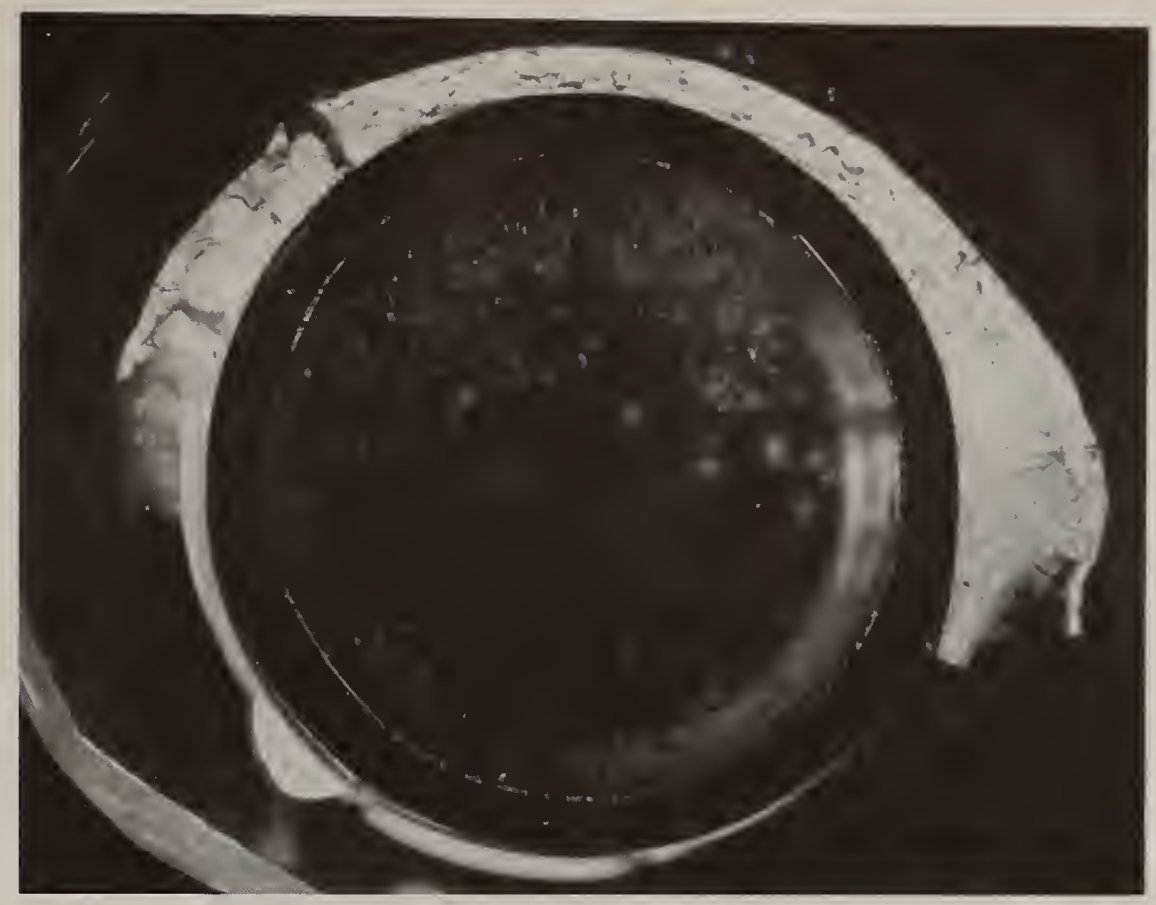

Fig. 12. Section of Type 304 stainless steel tubing after exposure to $\mathrm{K}_{2} \mathrm{CO}_{3} / \mathrm{K}_{2} \mathrm{SO}_{4}$ seeded fuel $r$ ich hot gas stream. Tube temperature $500^{\circ} \mathrm{C}$.

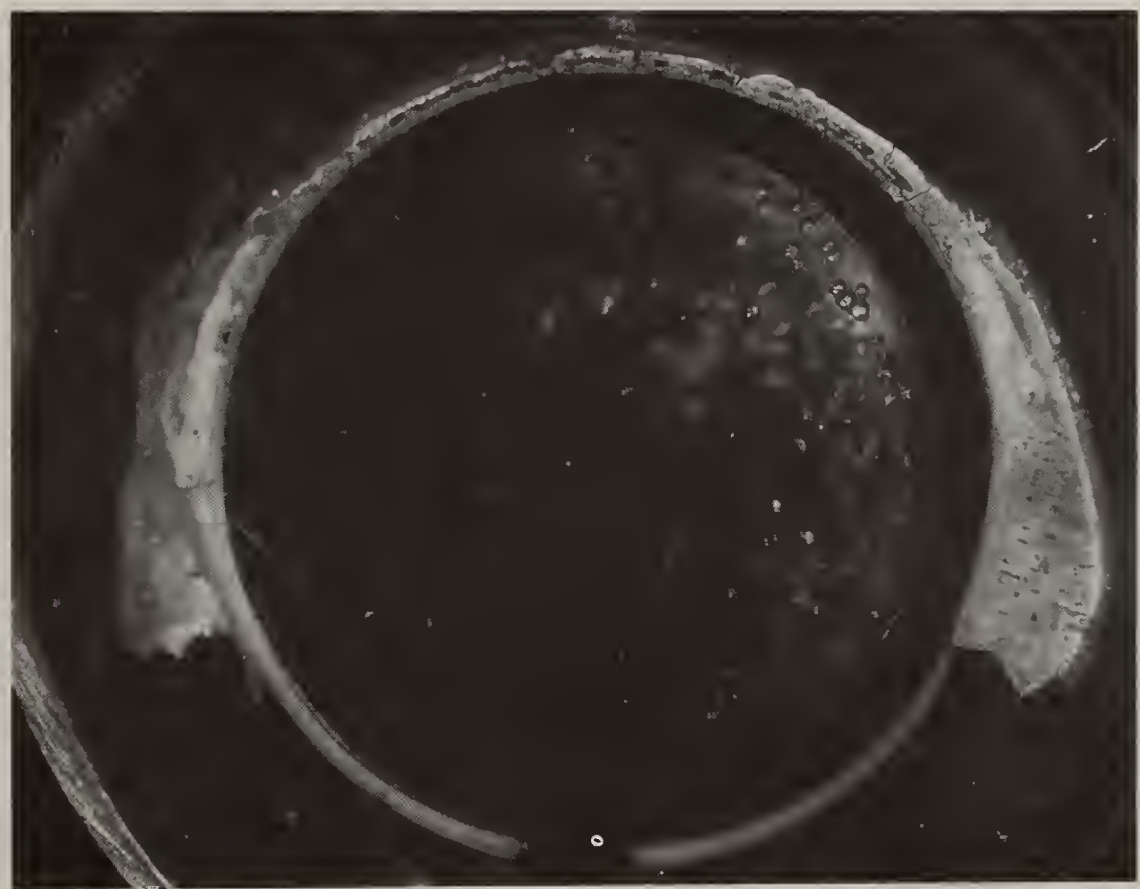

Fig. 13. Section of Type 304 stainless steel tubing after exposure to $\mathrm{K}_{2} \mathrm{CO}_{3} / \mathrm{K}_{2} \mathrm{SO}_{4}$ seeded fuel rich hot gas stream. Note formation of thin deposit on upper surface. Tube temperature $590^{\circ} \mathrm{C}$. $6 \mathrm{X}$. 


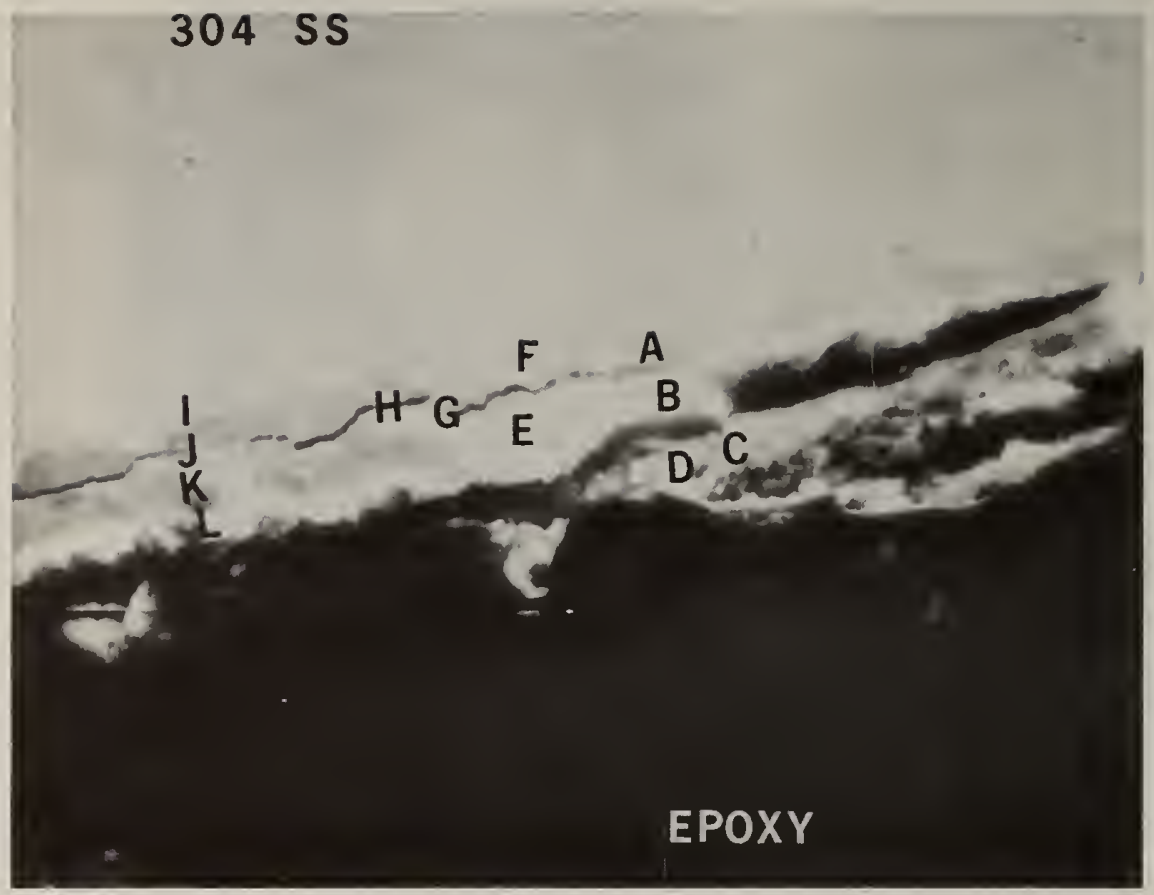

Fig. 14. SEM micrograph, $2000 X$, of stainless steel-salt deposit reaction zone. Lettered regions correspond to labeled EDX spectra, Figs. 14a to $14 \mathrm{f}$. Specimen temperature $500^{\circ} \mathrm{C}$; gas stream fuel rich.

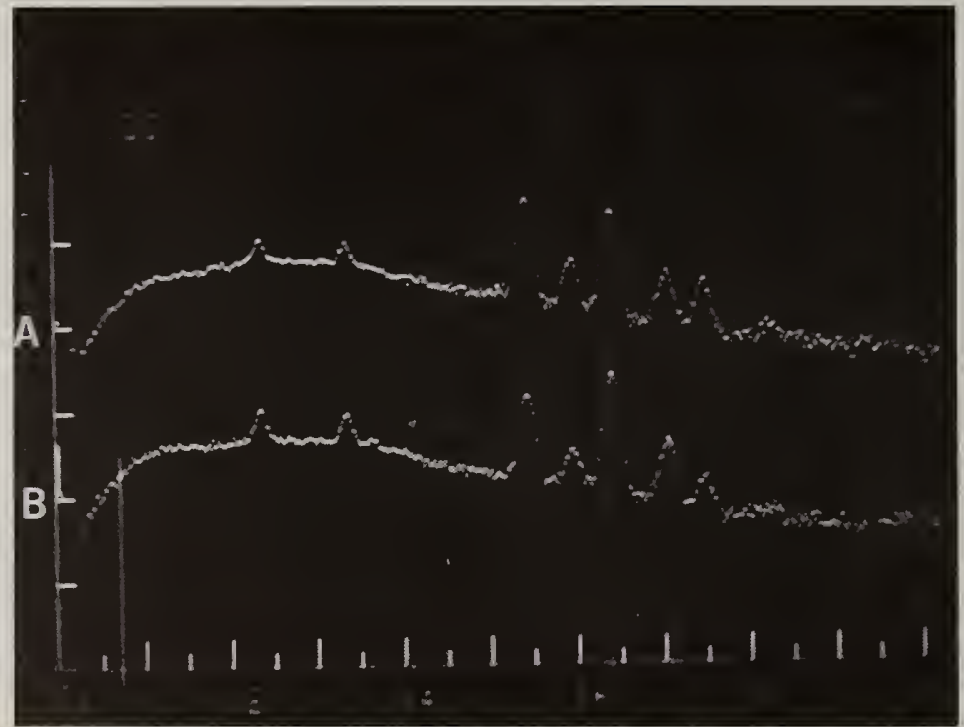

Fig. 14a. EDX spectra of regions $A$ and $B$ of Fig. 14 pointing out areas of high $\mathrm{Cr}$ concentration and $\mathrm{low} \mathrm{Ni}$ concentration on the stainless steel interface. 


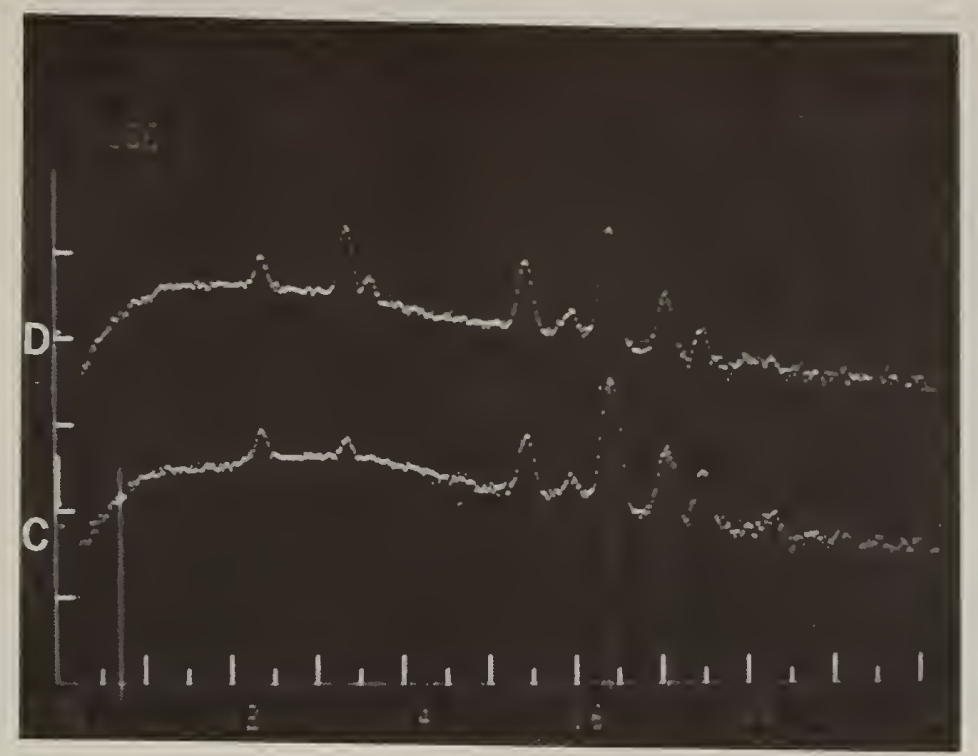

Fig. 14b. EDX spectra of regions $C$ and $D$ of Fig. 14 indicating areas of low $\mathrm{Cr}$ and low Ni concentration at the stainless steel interface.

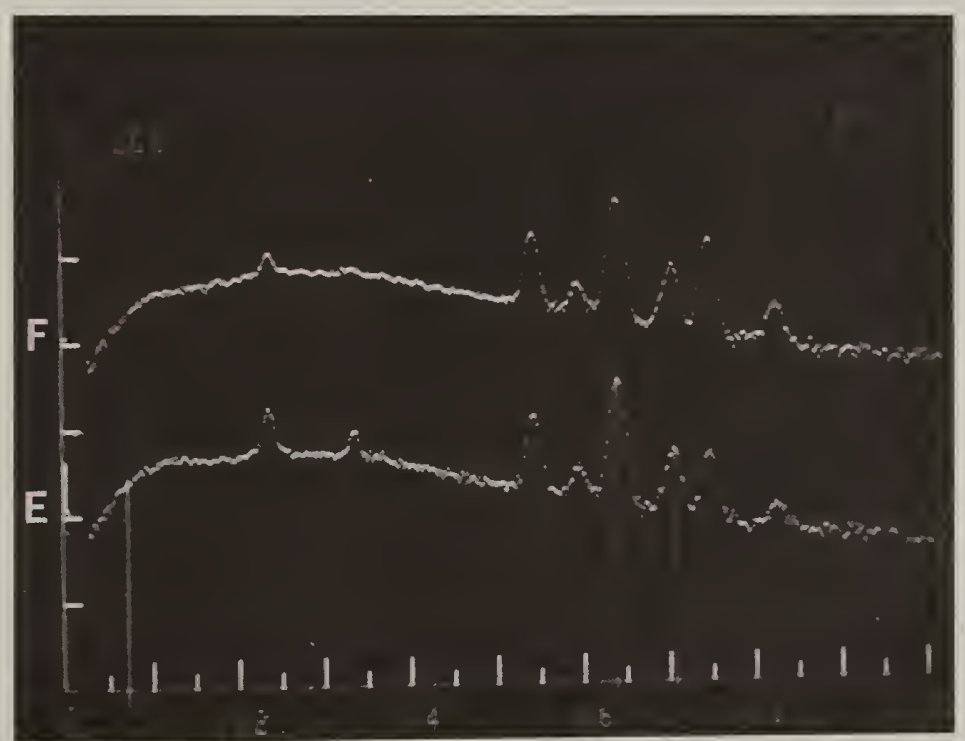

Fig. 14C. EDX spectra of regions $E$ and $F$ of Fig. 14 showing areas of high $\mathrm{Ni}$ and low $\mathrm{Cr}$ concentration at the stainless steel interface. 


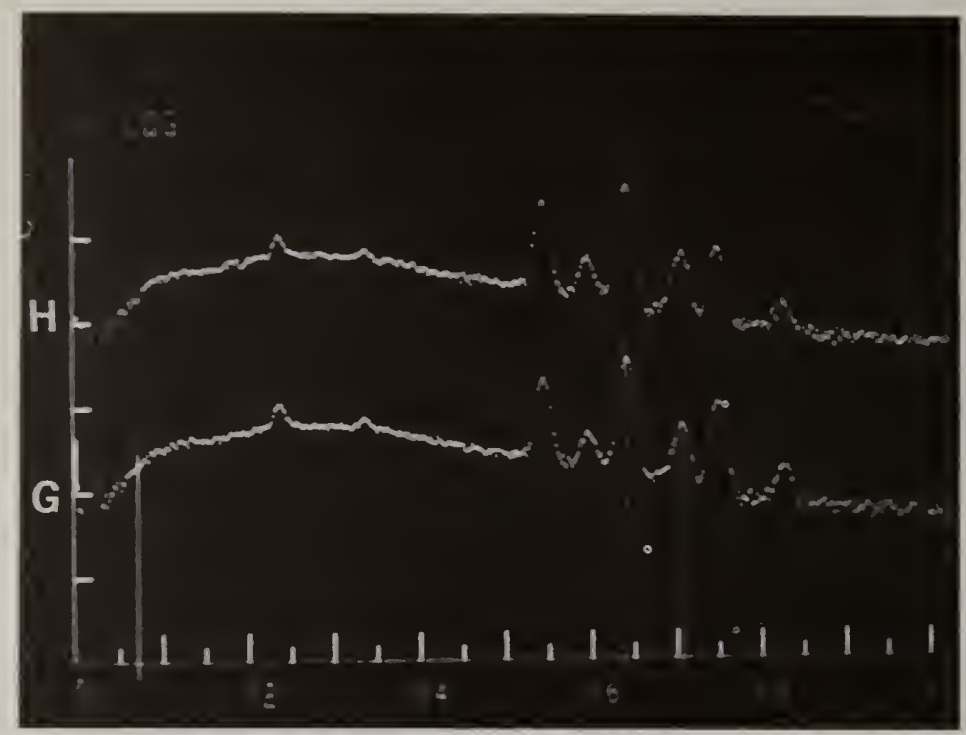

Fig. 14d. EDX spectra of regions $G$ and $H$ of Fig. 14 showing areas adjacent to $\mathrm{E}$ and $\mathrm{F}$ of high $\mathrm{Ni}$ concentration and $\mathrm{low} \mathrm{Cr}$ concentration.

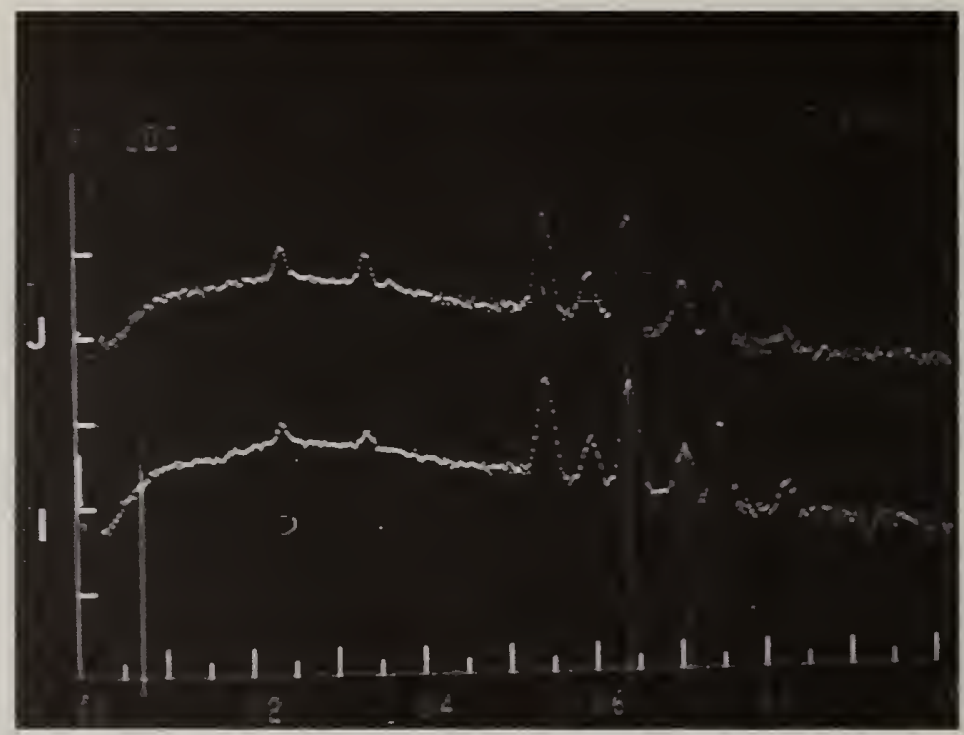

Fig. 14e. EDX spectra of regions I and $\mathrm{J}$ of Fig. 14 showing areas of high $\mathrm{Ni}$ and high $\mathrm{Cr}$ concentration at the interface. 


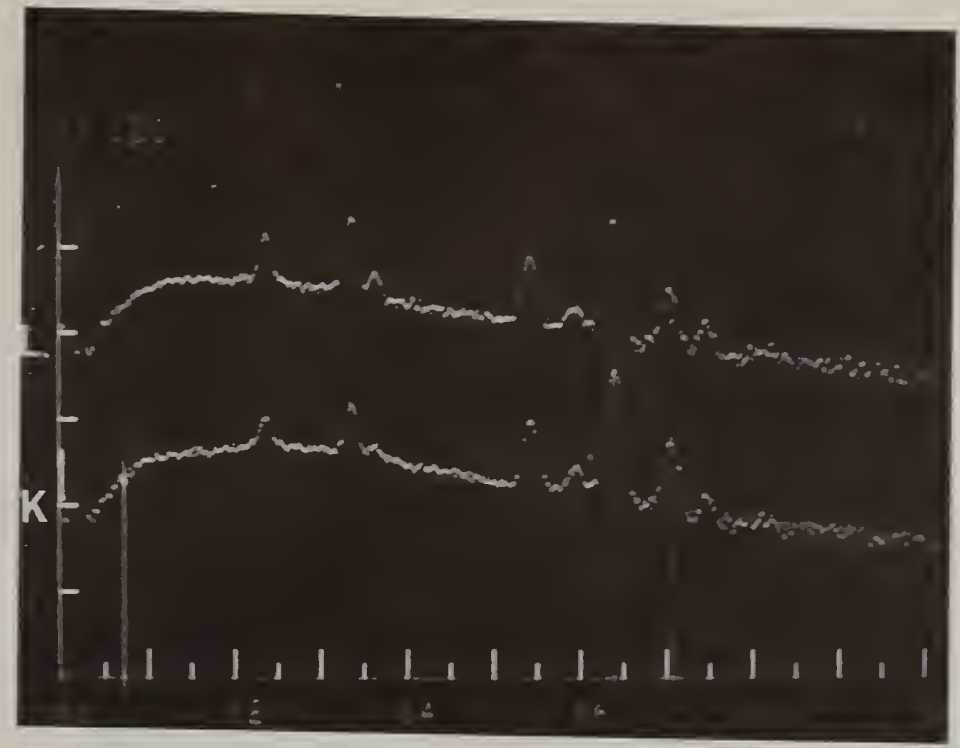

Fig. 14f. EDX spectra of regions $K$ and $L$ of Fig. 14 of areas below $I$ and $J$ showing low $\mathrm{Cr}$ and low $\mathrm{Ni}$ concentration.

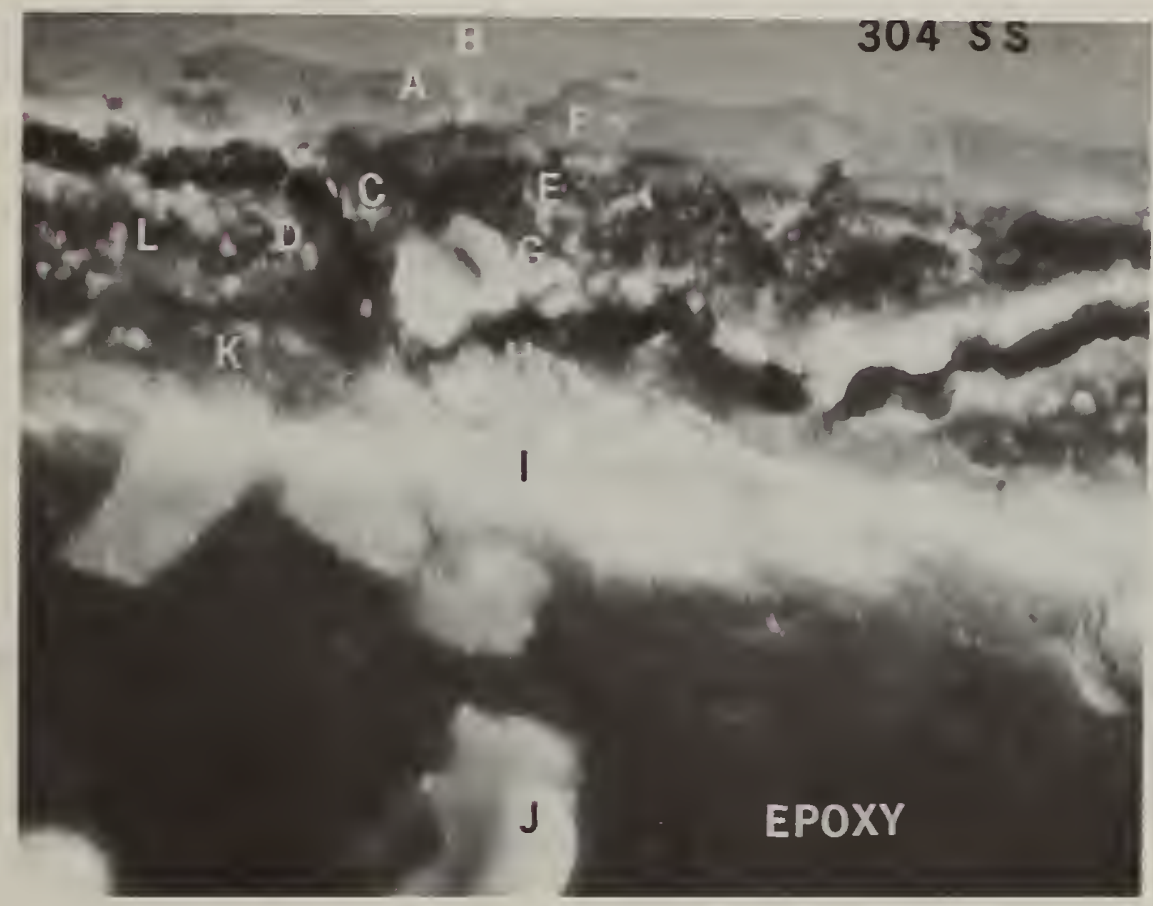

Fig. 15. SEM micrograph $2000 \mathrm{X}$, of stainless steel-salt deposit reaction zone. Lettered regions correspond to labeled EDX spectra, Figs. 15 a to $15 f$. Specimen temperature $590^{\circ} \mathrm{C}$ gas stream fuel rich. 


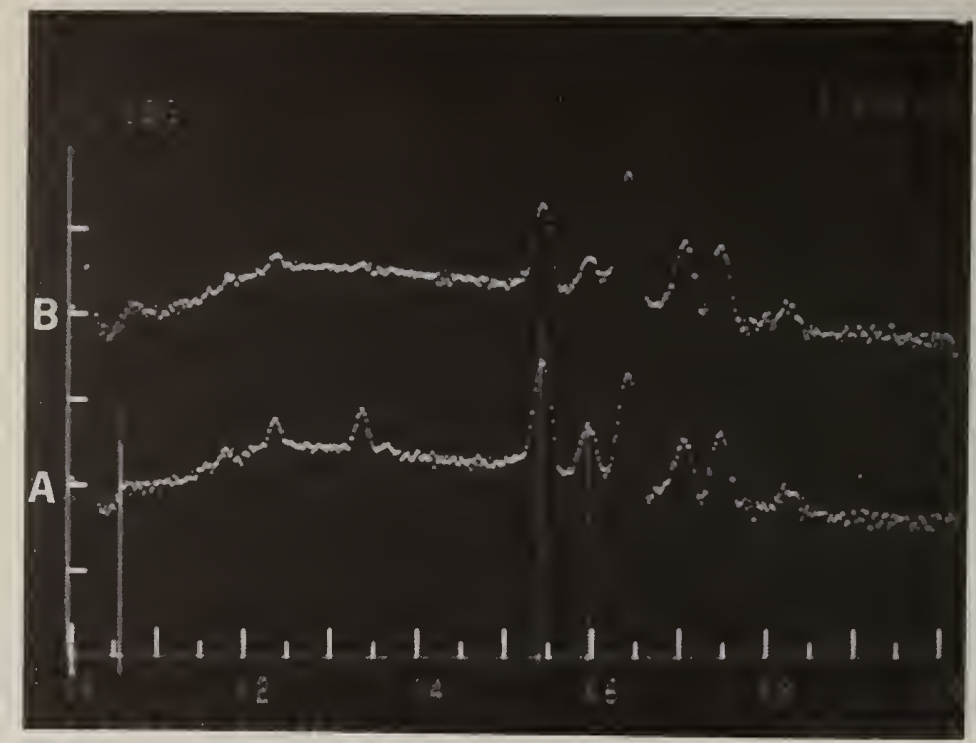

Fig. 15a. EDX spectra of regions $A$ and $B$ of Fig. 15 showing area of high $\mathrm{Cr}$ and high $\mathrm{Ni}$ concentration as compared to bulk stainless steel.

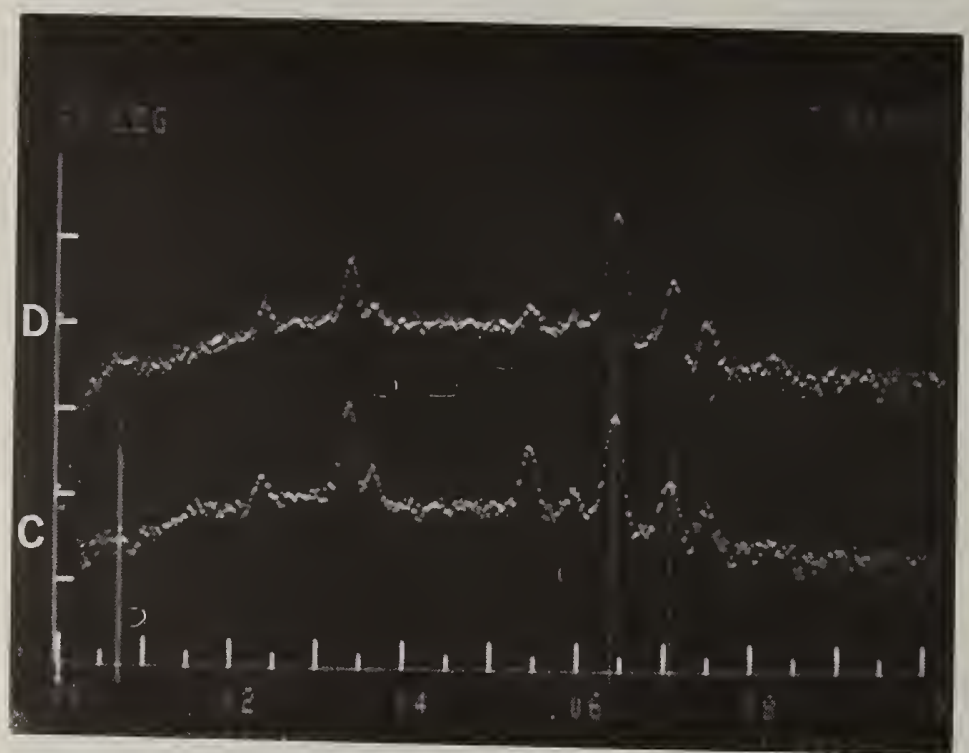

Fig. 15b. EDX spectra of regions $C$ and $D$ of Fig. 15 showing areas of high Fe, low $\mathrm{Ni}$ and low $\mathrm{Cr}$ concentration at the stainless steel-salt interface. 


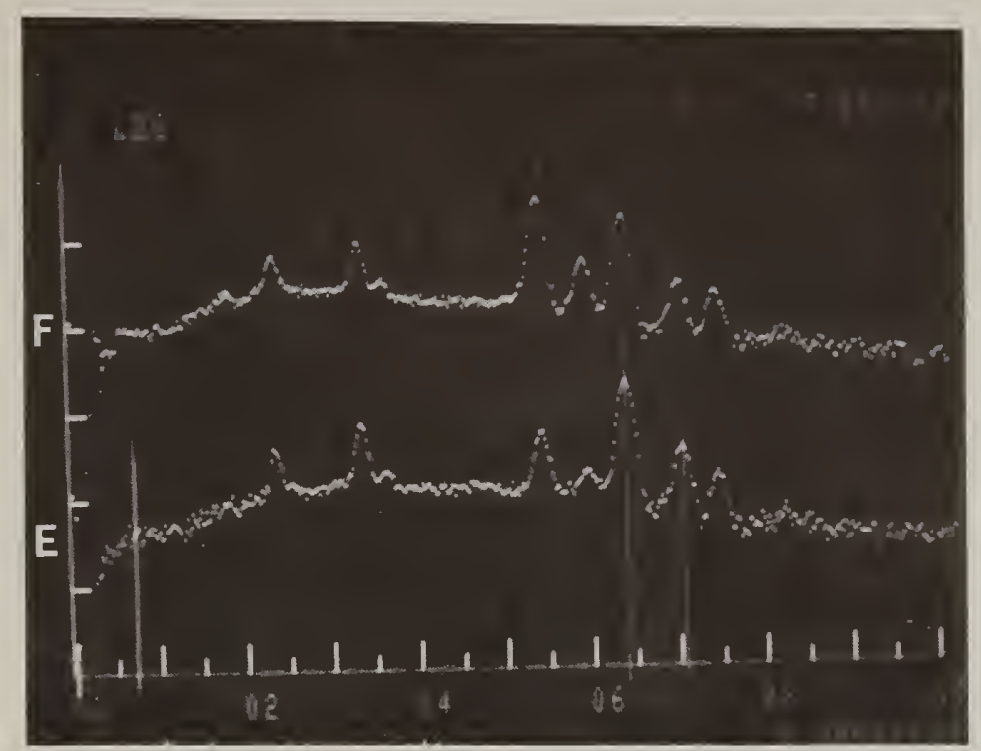

Fig. 15c. EDX spectra of region $\mathrm{E}$ of Fig. 15 indicating area of high $\mathrm{Cr}$ concentration with $\mathrm{Ni}$ and region $\mathrm{F}$ of $\mathrm{Fig} .15$ showing area of $10 \mathrm{~W} \mathrm{Cr}$ concentration with high $\mathrm{Ni}$ concentration.

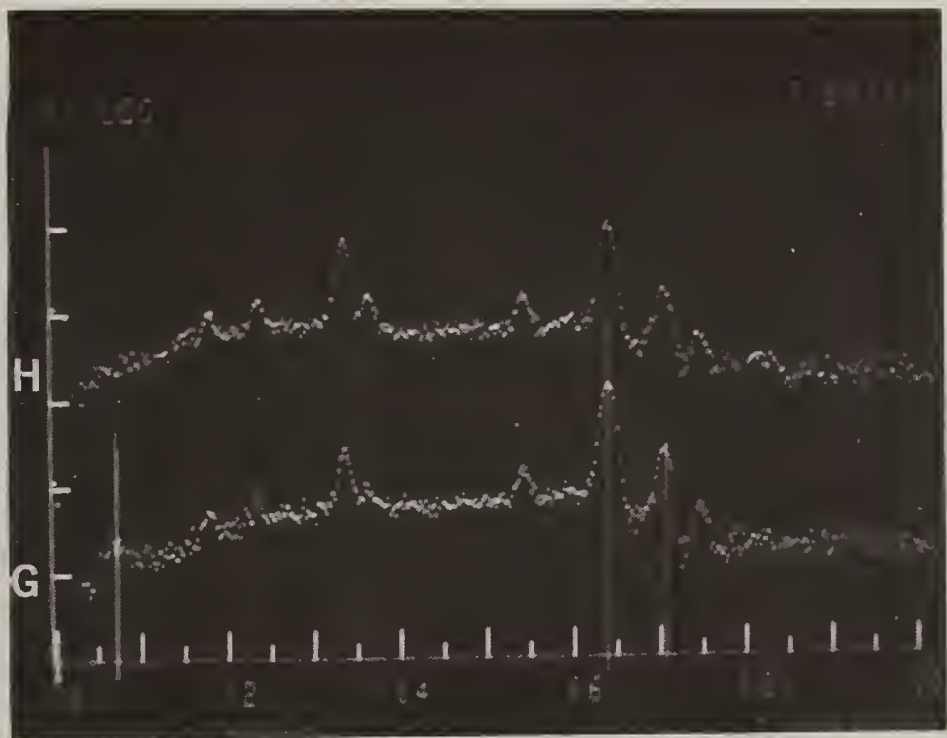

Fig. 15d. EDX spectra of regions $G$ and $H$ of Fig. 15 showing areas of high Fe and low $\mathrm{Ni}$ and low $\mathrm{Cr}$ concentrations at the stainless steel-deposit interface. 


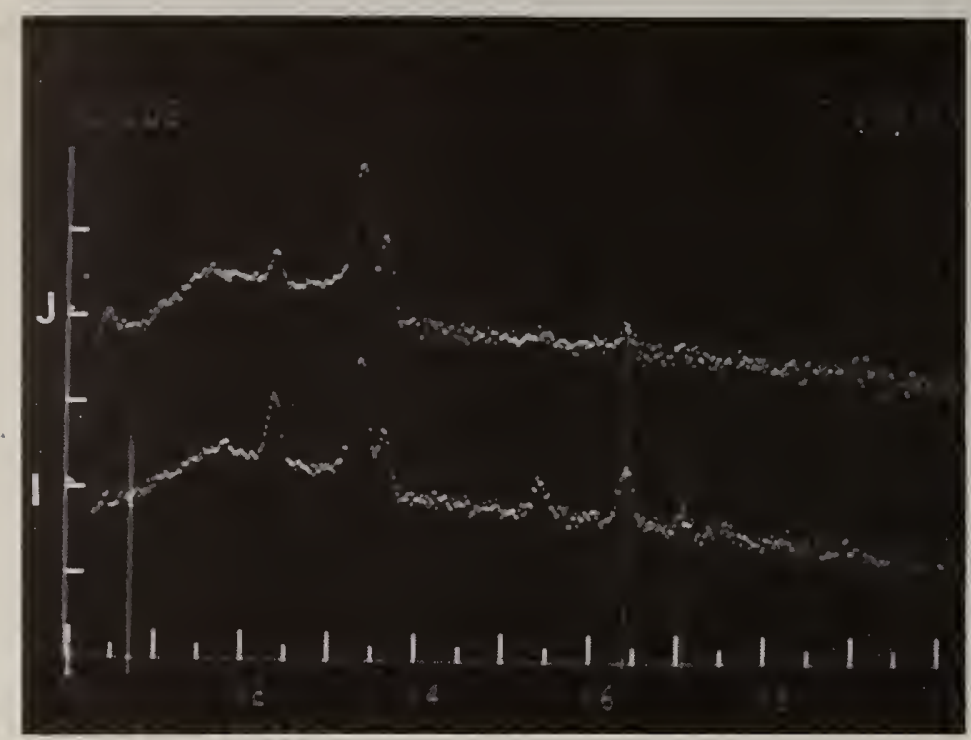

Fig. 15e. EDX spectra of regions I and $\mathrm{J}$ of Fig. 15 showing $\mathrm{Fe}$ and $\mathrm{Cr}$ penetration into the salt deposit.

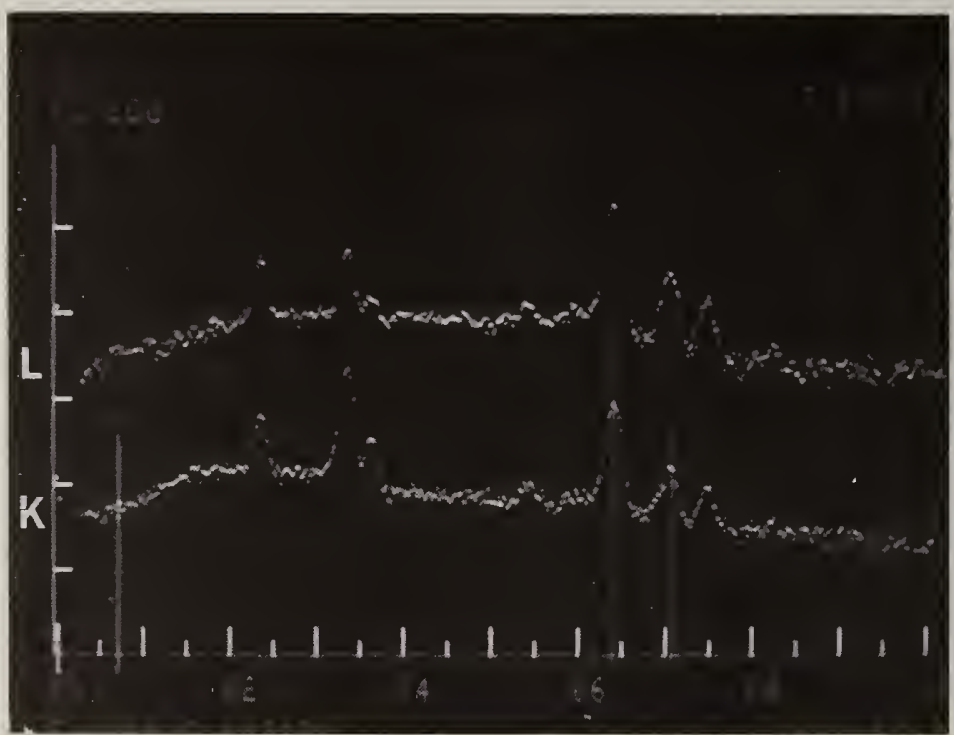

Fig. 15f. EDX spectra of regions $K$ and $L$ of Fig. 15 showing areas of high $N i$ and low $\mathrm{Cr}$ concentration at the stainless steel-salt interface. 


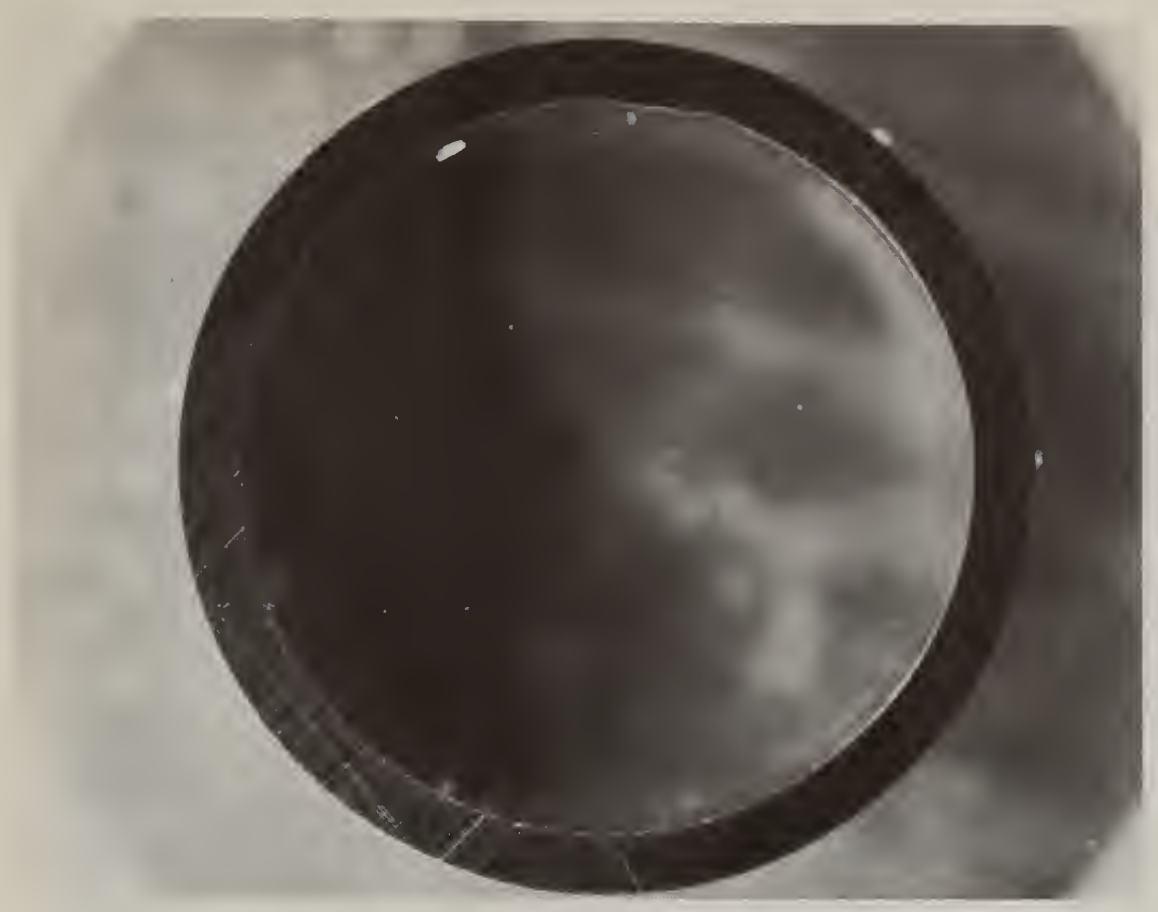

Fig. 16. Section of Type 304 stainless steel prior to exposure to the seeded hot gas stream. $6 \mathrm{X}$.

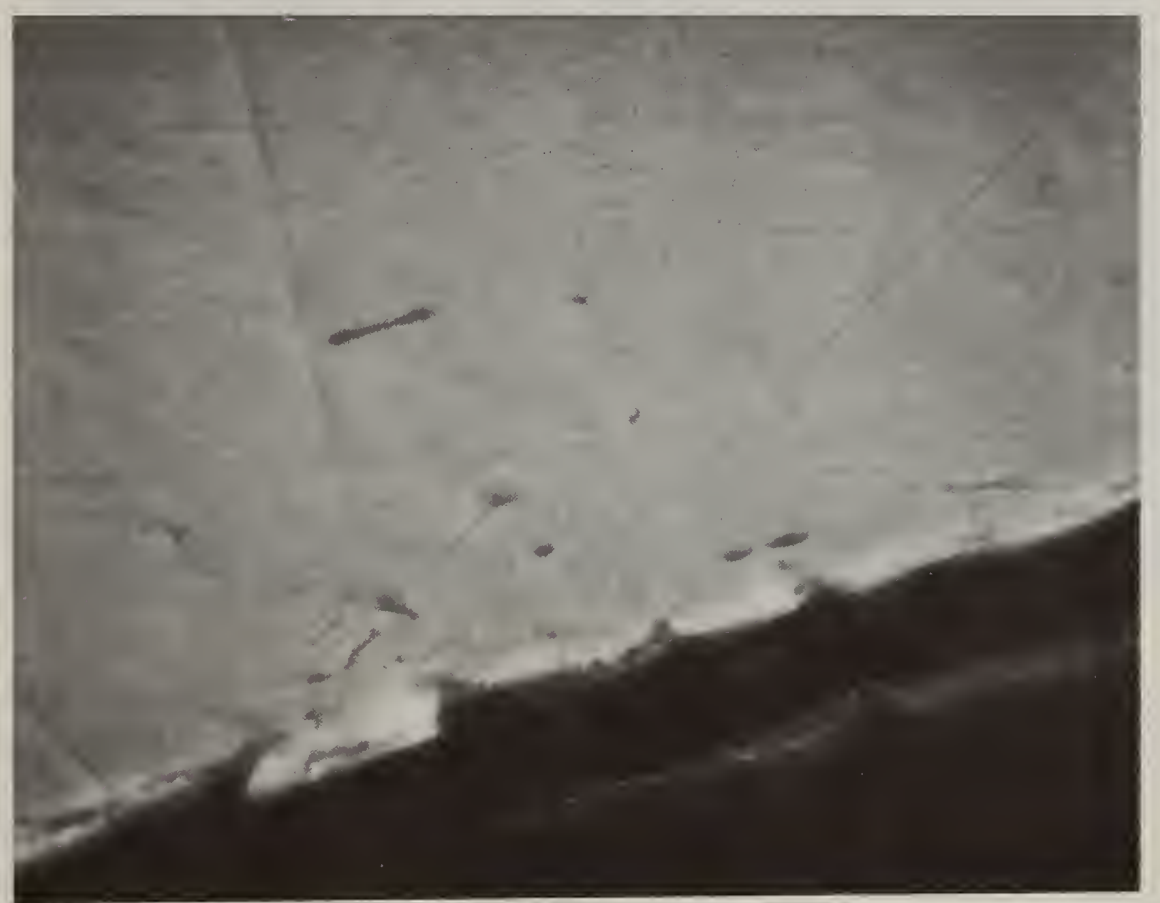

Fig. 17. SEM micrograph $4500 \mathrm{X}$, of section of Fig. 16 showing stainless steel edge. 


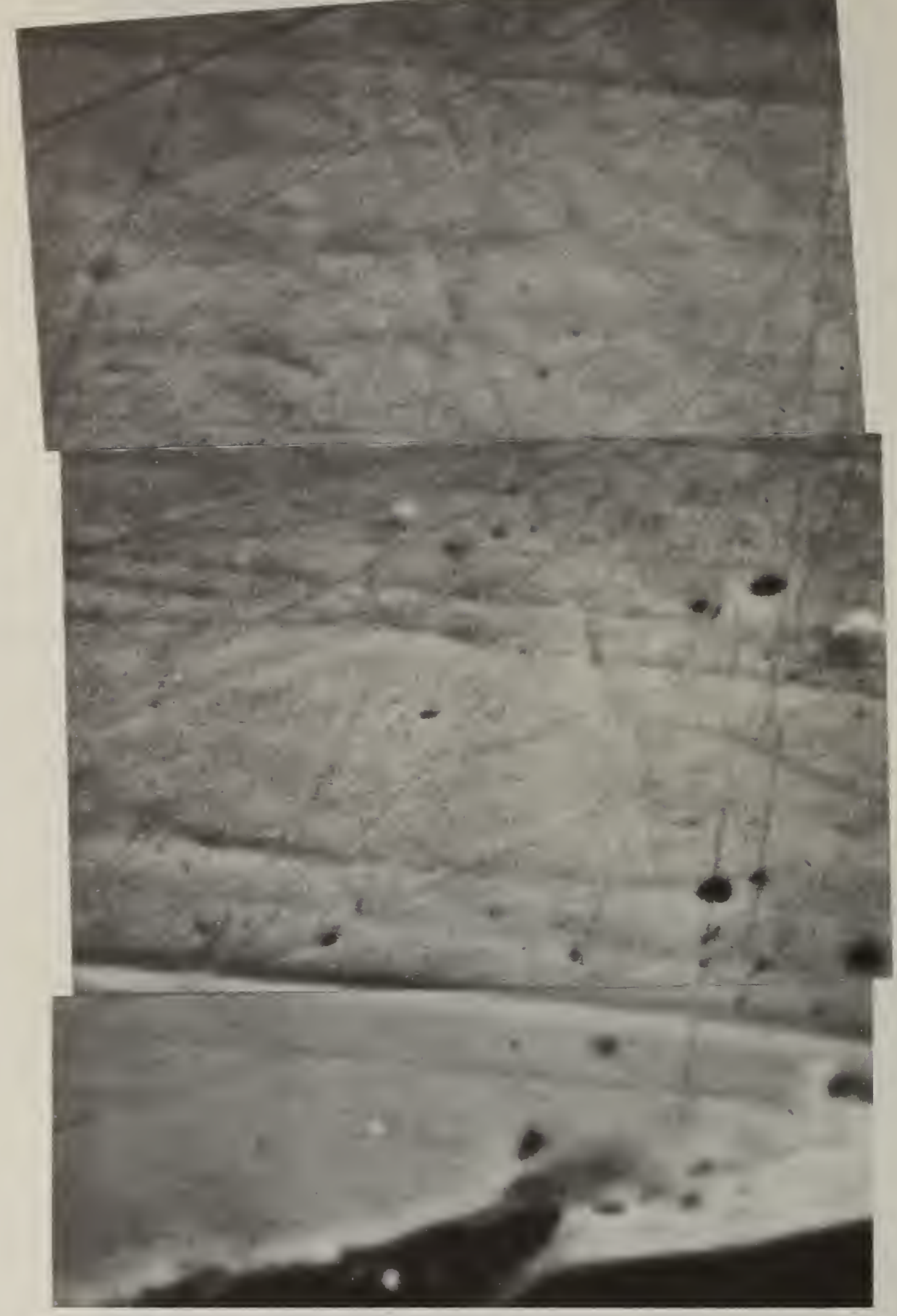

Fig. 18. SEM micrograph (montage) $9000 \times$, of a section of Fig. 16 showing inclusions and pits in the stainless steel. 


